\title{
Estimation of dimensions and orientation of multiple riverine dune generations using spectral moments
}

\author{
Aliaksandr Lisimenka ${ }^{1}$ - Adam Kubicki ${ }^{2}$ \\ Received: 25 May 2016/Accepted: 28 September 2016/Published online: 13 October 2016 \\ (C) The Author(s) 2016. This article is published with open access at Springerlink.com
}

\begin{abstract}
A new spectral analysis technique is proposed for rhythmic bedform quantification, based on the 2D Fourier transform involving the calculation of a set of low-order spectral moments. The approach provides a tool for efficient quantification of bedform length and height as well as spatial crestline alignment. Contrary to the conventional method, it not only describes the most energetic component of an undulating seabed surface but also retrieves information on its secondary structure without application of any band-pass filter of which the upper and lower cut-off frequencies are a priori unknown. Validation is based on bathymetric data collected in the main Vistula River mouth area (Przekop Wisły), Poland. This revealed two generations (distinct groups) of dunes which are migrating seawards along distinct paths, probably related to the hydrological regime of the river. The data enable the identification of dune divergence and convergence zones. The approach proved successful in the parameterisation of topographic roughness, an essential aspect in numerical modelling studies.
\end{abstract}

\section{Introduction}

Subaqueous rhythmic bedforms such as ripples and dunes (as in Ashley 1990) are important seafloor features which reflect physical phenomena taking place at the sediment-water interface and, at the same time, modulate these phenomena (Allen

Aliaksandr Lisimenka

sasha@im.gda.pl

1 Maritime Institute in Gdańsk, Długi Targ 41/42, 80-830 Gdańsk, Poland

2 GEO Ingenieurservice Nord-West, Wilhelmshaven, Germany
1982). Due to changes in elevation along bedforms, modification of the pressure distribution is observed. It is reflected in a decrease of pressure and consequently in flow acceleration on the stoss face, and an increase of pressure and flow deceleration downstream of the bedform crest (e.g. Vanoni and Hwang 1967; Best 2005). The presence of bedforms therefore strongly influences the form drag, impacting directly on the overall flow resistance as well as the flow velocity structure and sediment transport pattern (e.g. Venditti 2007; Bartholdy et al. 2010; Lefebvre et al. 2016). Detailed characterisation of bedform roughness reflected in bedform parameters of their spatial distribution and orientation is therefore vital for constructing numerical models of flow field, hydrology and sediment transport.

Since 1977 when the first world ocean floor map was compiled by Mary Tharp and Bruce Heezen based on single-beam echosounder data (see Blondel 2009), methods for bathymetry mapping have improved significantly. Development of highresolution sonar systems and satellite positioning methods led to the availability of precise techniques for seafloor relief data acquisition. Swath bathymetry systems (multi-beam echosounders, MBES) have become a widely used tool for high-resolution, rapid and cost-effective mapping of submerged environments. It has become possible to investigate quantitatively in far more detail important aspects of bottom surface roughness and to verify geomorphological processes responsible for bedform formation through interactions between sediments and water flow (e.g. Bartholomä et al. 2004; Knaapen et al. 2005; Parsons et al. 2005; Knaapen 2008; Barnard et al. 2011).

Many investigators approached the characterisation of bedform roughness based on spectral analysis decomposing the seafloor relief into its major spatial frequency components, which opened possibilities for better identifying and describing morphological features. Bottom roughness description 
through spectral analysis techniques was first reported by Nordin and Algert (1966), who identified variability in a sand wave bed formed under a unidirectional flow regime based on spectral density function calculations. In turn, Hino (1968) first proposed a "power law" function in representing a bottom roughness spectrum. Later, Fox and Hayes (1985) developed a valid stochastic description of several single bathymetric profiles based on a statistical measure of bottom roughness from the slope of the amplitude spectrum, and showed evidence of power-law behaviour for roughness in the $10 \mathrm{~cm}$ to $200 \mathrm{~m}$ length range. As argued by Briggs (1989), however, the data in the highest frequencies (for lengths from $10 \mathrm{~cm}$ to $1 \mathrm{~mm}$ ) were too scarce to be conclusive. Briggs et al. (2002) split the seafloor roughness spectrum into multiple frequency bands and fitted power-law relationships to the measured spectra. In turn, Lyons et al. (2002) highlighted that it is advantageous to model naturally rippled sediment surfaces by a two-component spectrum comprised of a non-centred Gaussian component and an isotropic power-law component.

Contrary to the one-dimensional approach, the earliest successful attempt to quantify seabed roughness based on usage of a two-dimensional power spectrum and related autocorrelation function obtained from pairs of stereo microtopography photographs of the bottom was done by Akal and Hovem (1978). This was confirmed and expanded by numerous studies related to bedform characterisation based on the algorithm of the two-dimensional discrete Fourier transform (2D DFT) spectral analysis (e.g. Cazenave et al. 2008; Van Dijk et al. 2008; Lefebvre and Lyons 2011; Lefebvre et al. 2011; Lisimenka et al. 2013). Extant quantitative analysis techniques and methodologies for the semi-automated and objective description of primary parameters such as length, orientation, crest and trough position, height, asymmetry direction and asymmetry ratio, which are commonly used to describe bedforms on subaerial and subaqueous roughness surfaces, were adapted and proposed recently by Cazenave et al. (2013). However, one of the disadvantages of current methodologies is the need to apply band-pass filtering in order to quantify secondary and potential further generations (distinctive groups) of rhythmic bedforms.

The present study reports a newly developed concept for quantitative analysis of subaqueous straight-crested undulating bottom roughness using the 2D DFT algorithm, which involves calculation of low-order spectral moments. Based on a two-dimensional spectrum estimated from a height field and a set of one-dimensional "slices" executed from the 2D spectrum with one-degree step, spectral moments of different orders are calculated in order to determine the primary parameters of the observed bedforms, such as crest-line spatial alignment, length and height. Contrary to previous studies, this approach provides a possibility not only to quantify primary generations, i.e. the most energetic component of the undulating sea-bottom surface, but also to obtain information about secondary and further generations (i.e. groups of dunes with common parameters) without application of a band-pass filter of which the upper and lower cut-off frequencies are a priori unknown. The method was developed to identify and quantify various generations of subaqueous dunes in the Vistula River mouth, Poland.

\section{Physical setting}

Field investigations were carried out in the main mouth of the Vistula River (Przekop Wisły) located in Polish coastal waters (Fig. 1). The Vistula is the largest river of the southern Baltic Sea and one of the least regulated amongst large rivers in Europe. With a total length of $1,047 \mathrm{~km}$, the Vistula plays a dominant role with regards to both the catchment area of $194,424 \mathrm{~km}^{2}$ and the quantity of discharged fresh water flowing into Gdańsk Bay (Fig. 1a). The average yearly river runoff amounts to $34 \mathrm{~km}^{3}$ (Majewski 2013).

The main river mouth "Przekop Wisły" is a cross-cut artificial channel of ca. 3,000 m length, $400 \mathrm{~m}$ width and temporarily up to $10 \mathrm{~m}$ depth (Fig. 1c). Due to locks controlling water levels in the old channels of the Vistula (Nogat, Szkarpawa and Martwa Wisła, Fig. 1b), about $95 \%$ of the total Vistula water outflows into the Baltic Sea through this channel. The closest gauging station is located in Tczew $31.2 \mathrm{~km}$ upstream of the Vistula channel mouth (Fig. 1b). It represents 99.92\% of the catchment area (Augustowski 1982). Based on operational data obtained from this gauging section (IMGW-PIB 2015), the long-term average annual water discharge reaches $1,042 \mathrm{~m}^{3} / \mathrm{s}$. The average daily water discharge, however, varies from $266 \mathrm{~m}^{3} / \mathrm{s}$ in the dry season to $6,360 \mathrm{~m}^{3} / \mathrm{s}$ during floods. The river plays a crucial role also in sediment delivery processes as the Vistula carries $0.6-1.5 \times 10^{6} \mathrm{~m}^{3}$ of sediments annually (Pruszak et al. 2005), thereby expanding the delta front (Wróblewski et al. 2015).

\section{Hydrological regime of lower Vistula}

The time series of Vistula River discharge values (Fig. 2) collected at the Tczew gauge (Fig. 1b) during a period of 18 months prior to the present measurements revealed a slight bimodality of the hydrological regime. The most common discharges (25\% of the tested period occurrence) were between 500 and $700 \mathrm{~m}^{3} / \mathrm{s}$ (Fig. 2b) and they occurred mostly in autumn and winter 2011. The second mode of discharge between 1,100 and $1,400 \mathrm{~m}^{3} / \mathrm{s}$ is related to spring snow melt and precipitation floods, as well as floods due to ice and frazil jams. Several flood events were recorded, with the most energetic event of $4,200 \mathrm{~m}^{3} / \mathrm{s}$ in 
a)

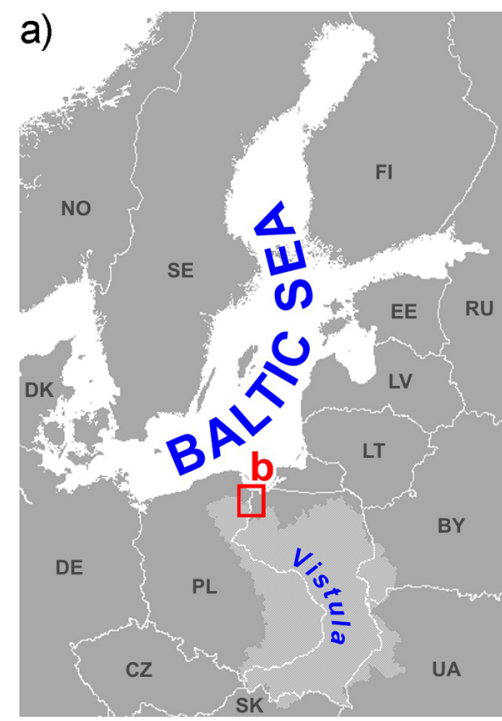

b)

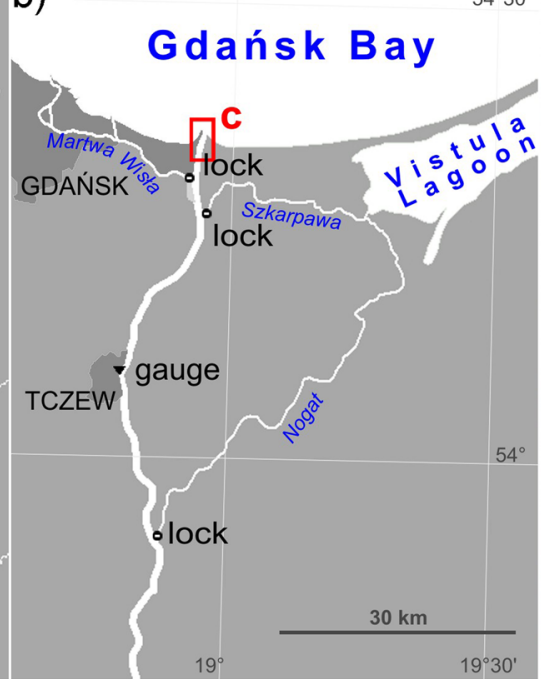

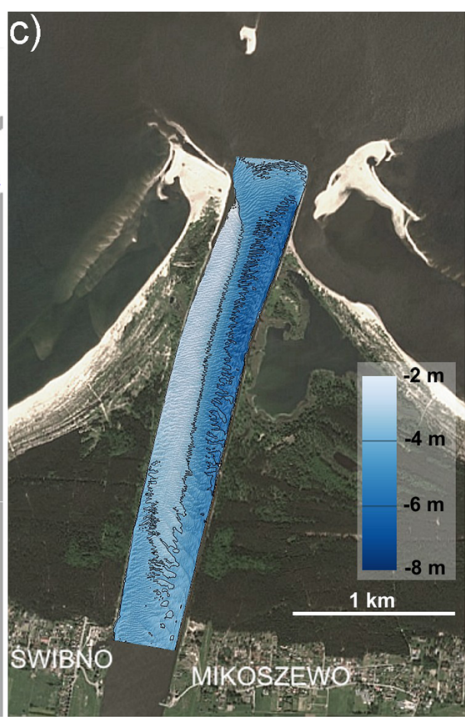

Fig. 1 a Location of the study area in the southern Baltic Sea and b with respect to old channels of the Vistula River. c Bathymetry of Przekop Wisły overlying an aerial photograph of May 2013 (source: Google Earth)

January 2011 and four other flood waves exceeding 2,000 $\mathrm{m}^{3} / \mathrm{s}$. The gauge located upstream from the study area failed to reproduce the backflow phenomena frequently affecting the river mouth during storm surges in Gdańsk Bay. This occurs when strong westerly winds blowing for a long period of time cause a run-up in the bay and subsequent northerly winds push the excess water masses into the river. There are, however, no data available on current directions at the river mouth prior to the present measuring campaign.

\section{Materials and methods}

\section{In situ measurements}

The measurement campaign in the Vistula River mouth was carried out on 4-6 June 2012. The bathymetry was mapped using a Reson SeaBat 7101 multi-beam echosounder (MBES) operating at $240 \mathrm{kHz}$. The sonar provides 511 discrete sounding beams across the wide $150^{\circ}$ swath with $1.5^{\circ}$ along-track

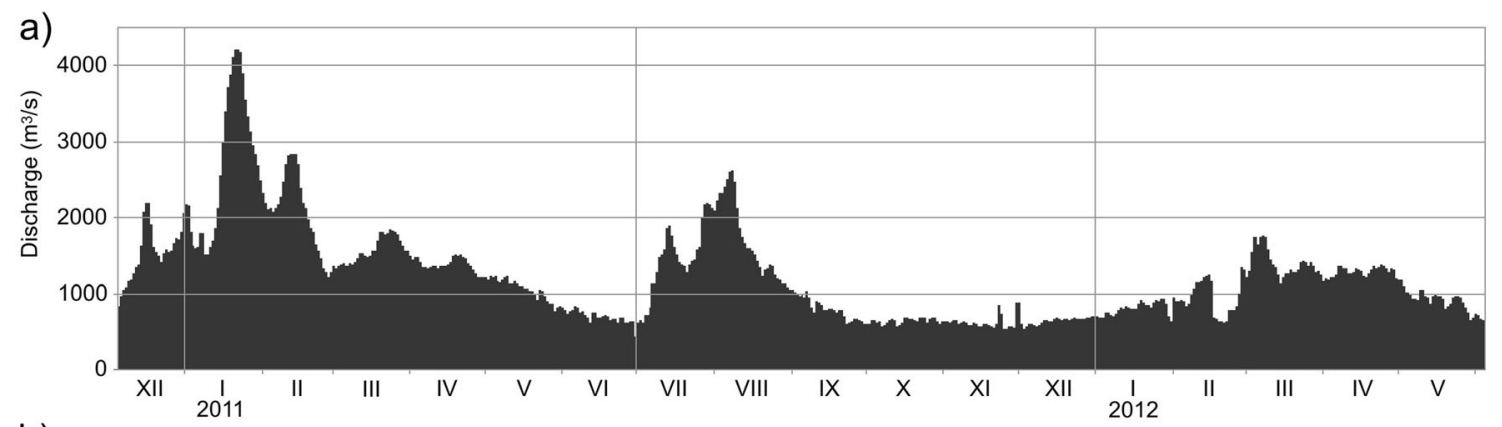

b)

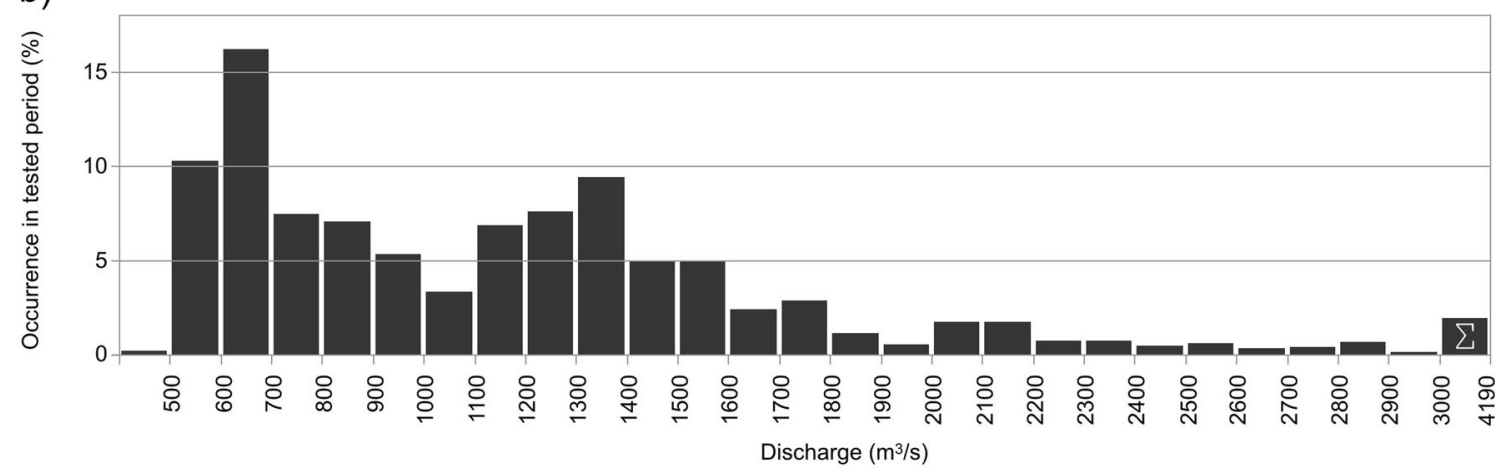

Fig. 2 a Hourly discharges of the Vistula River at the Tczew gauge between December 2010 and May 2012 and $\mathbf{b}$ variations in discharge in $100 \mathrm{~m}^{3} / \mathrm{s}$ intervals (courtesy of IMGW-PIB, Institute of Meteorology and Water Management-National Research Institute) 
transmit beam width, $1.8^{\circ}$ across-track receive beam width and $0.0125 \mathrm{~m}$ depth resolution. The sound velocity probe Reson SVP-70 was fixed to the MBES head, and the portable sound velocity profiler Reson SVP-15 was used to obtain the sound speed at the depth of the MBES draft and through the water column. The positioning system DGPS RTK Trimble SPS 851 together with the Ixsea Hydrins inertial navigation system were integrated with the MBES and SVPs using the QINSy data acquisition software package. Full coverage of the area of interest was achieved. The post-processing of the MBES raw data was performed in the QINSy Processing Manager according to standard procedures widely used in hydrography.

\section{Bedform parameters}

A digital terrain model (DTM) of the riverbed was obtained from the high-resolution multi-beam echosounder data. The bathymetric data were gridded with a cell size of $0.1 \mathrm{~m}$. This was justified by the high density of individual soundings - in $99.7 \%$ and $83.2 \%$ of cases, at least 100 soundings per $\mathrm{m}^{2}$ were collected in shallow waters (shallower than $-3 \mathrm{~m}$ depth) and deep waters (deeper than $-7 \mathrm{~m}$ depth) respectively.

The entire riverbed elevation dataset was subsequently divided into sub-domains using a sliding square window of $200 \times 200 \mathrm{~m}$ size with a $75 \%$ overlap between adjacent windows. The chosen size of the window was a result of compromise between the overall area extent and the observed bedform lengths.

Within each of the test boxes, the mean depth was subtracted from each data sample and then the bathymetric surface was detrended in $2 \mathrm{D}$ by fitting and removing a third-order polynomial regression model. In order to minimize spectral leakage due to the finite length of the dataset, data in each sub-domain were pre-multiplied by a single orthogonal taper belonging to a family of functions known as discrete prolate spheroidal sequences (DPSS or Slepian sequences; Percival and Walden 1993). Among numerous existing window functions, the DPSS is a unique taper function which offers the best side-lobe suppression (maximization of energy concentration in the main lobe of the window function frequency response). In fact, "windowing" reduces bias but, on the other hand, it causes a reduction of resolution in the spectral estimate which becomes smoother (the variance of the periodogram increases). Therefore, according to Lyons et al. (2002), it is desirable to apply the widest data taper which reduces bias to an acceptable level for estimation of accurate frequency components.

A two-dimensional zero-order DPSS window function with the time half bandwidth product $T W=2.5$ was computed by taking the outer product of one-dimensional tapers for each dimension, and its weighting coefficient $w_{\text {coeff }}$ was determined as:

$w_{\text {coeff }}=\frac{1}{M N} \sum_{x=1}^{M} \sum_{y=1}^{N} F_{\text {taper }_{\mathrm{x}, \mathrm{y}}}$

where $M$ and $N$ are the number of samples in $x$ and $y$ directions respectively, and $F_{\text {taper }}$ are two-dimensional taper function values.

Subsequently, spectral analysis based on the 2D DFT (performed with the Matlab ${ }^{\circledR} f f 2$ function) was executed, yielding a two-dimensional power spectrum function which describes the seabed height field in the space frequency domain. In order to minimize any false components in the spectra associated with the border of the data coverage effect, the 2D DFT was calculated only in sub-domains with data coverage greater than $75 \%$. In this way, 331 sub-domains were analysed.

Taking into account that the window function was applied, and in order to recover the height of bedforms in a sufficient way, the power spectrum function must be multiplied by the reciprocal of the weighting coefficient $w_{\text {coeff }}$ (Eq. 1):

$P\left(f_{\mathrm{x}}, f_{\mathrm{y}}\right)=\frac{1}{w_{\text {coeff }}}|\mathfrak{I}\{s(x, y)\}|^{2}$

where $P\left(f_{\mathrm{x}}, f_{\mathrm{y}}\right)$ is the $2 \mathrm{D}$ (two-sided) power spectrum function estimated from the seabed height field $s(x, y)$ referred to an appropriate spatial frequencies $f_{\mathrm{x}}$ and $f_{\mathrm{y}}$; the $\mathfrak{I}$ symbol represents the 2D DFT routine.

Owing to the spectrum symmetry related to the DC component $f(0,0)$, only the upper semi-plane of the twodimensional spectrum was further considered. Then, a set of 180 one-dimensional "slices" $P_{\theta \mathrm{i}}$ with one-degree step based on the Bresenham's line algorithm was extracted from the $2 \mathrm{D}$ spectrum, where $i \in[0: 1: 180)$ designates the appropriate alignment angle $\theta_{\mathrm{i}}$ of the $i$ th slice. For the sake of clarity, a multiplication factor of 2 is taken further into account as well, i.e. $P=2 P$, thereby obtaining a one-sided power spectrum. Because of the twodimensional task, the distance between adjacent discrete points in each one-dimensional slice is different, while the number of points in the case of "half of the spectrum" is defined from the NFFT/2. Therefore, in order to exclude any uncertainties connected with the "sampling directional problem", particular discretised frequencies $f_{\theta \mathrm{i}}$ with an appropriate $\Delta f_{\theta \mathrm{i}}$ interval for each $i$ th slice were calculated based on simple geometry. Then, a variance spectrum $S$ with units $\mathrm{m}^{3}$ was determined for each "slice" by scaling a power spectrum with the Nyquist frequency:

$S_{\theta_{\mathrm{i}}}\left(f_{\theta_{\mathrm{i}}}\right)=\frac{P_{\theta_{\mathrm{i}}}}{F_{\mathrm{s}} / 2}$ 
At the next step, several spectral parameters were derived from the spectral function based on the calculation of spectral moments and their combinations. One of the well-known advantages of spectral moments, which retrieve information directly from the Fourier spectrum, is their insensitivity to signal phase changes. These can be often distorted by "usual" filtering, thereby falsifying the amplitude spectrum. Moreover, by conducting complete analogy between the power spectrum density and the probability density function, they can also be viewed as statistical descriptors of spectral function.

Applying spectral moments to quantify heights of regularly spaced seabed dunes was in direct analogy to hydrodynamics applications, where they are widely used for spectral parameterisation of sea surface waves (e.g. Massel 2013). In the general case of a one-sided spectrum, the spectral moment of $r$ th order, $m_{\mathrm{r}}$, with respect to the frequency origin is defined as:

$m_{\mathrm{r}}=\int_{0}^{\infty} f^{\mathrm{r}} S(f) \mathrm{d} f$

By definition, the zero moment of the spectrum $m_{0}$ represents the signal energy across the entire frequency domain of the spectrum, and it is also equal to the variance of the random process:

$m_{0}=\int_{0}^{\infty} S(f) \mathrm{d} f=\sigma_{\zeta}^{2}$

In turn, the second spectral moment is determined as:

$m_{2}=\int_{0}^{\infty} f^{2} S(f) \mathrm{d} f$

The physical meaning of the $m_{2}$ can be interpreted as a weighting of each frequency content in the spectrum by the second power of the frequency, thereby "amplifying" a high-frequency tail, the spectral power of which is usually significantly lower in comparison with the more energetic low-frequency part of the spectrum. Consequently, it enables extraction of information about the presence of smaller dune lengths in the spectral curve, which can be of particular interest as well.

In the case of discrete data series, the zero moment of the spectral function retrieved from the undulation spectrum "slice" $S_{\theta \mathrm{i}}$ with the alignment angle $\theta_{\mathrm{i}}$ can be expressed as:

$m_{0}\left(\theta_{\mathrm{i}}\right)=\sum_{f_{\theta_{\mathrm{i}}}=f_{\text {thresh }}}^{F_{\mathrm{s}} / 2} S_{\theta_{\mathrm{i}}}\left(f_{\theta_{\mathrm{i}}}\right) \Delta f_{\theta_{\mathrm{i}}}$

where the whole frequency range is limited by low-frequency $f_{\text {thresh }}$, which corresponds to the largest dune length of interest $\lambda_{\text {thresh }}=75 \mathrm{~m}$, and $F_{\mathrm{s}} / 2$, the Nyquist frequency. Thus, frequencies $f<f_{\text {thresh }}$ corresponding to lengths larger than $\lambda>\lambda_{\text {thresh }}$ were not taken further into consideration.

The choice of $f_{\text {thresh }}$ is based on a compromise between the size of the analysed sub-domains $(200 \times 200 \mathrm{~m})$ and the minimization of space alignment angle and dune length uncertainties. An effect of varying length as a function of domain size on both alignment and length uncertainties was examined by Cazenave et al. (2013). Using the approach of those authors, the alignment angle and length uncertainties do not exceed $26 \%$ and $35 \%$ respectively for the largest dune length of interest in the present case, i.e. $\lambda_{\text {thresh }}=75 \mathrm{~m}$, which is $37.5 \%$ of the sub-domain size. In the case of the calculated median length $\lambda_{\text {median }}=30 \mathrm{~m}$ (15\% of the sub-domain size), the alignment angle and length uncertainties decrease significantly to less than $10 \%$ and $12.5 \%$ respectively. In the general case, since the uncertainties are a function of the sub-domain selected for the analyses, choosing a larger sub-domain would decrease those uncertainties.

Because the normalized first-order spectral moment $m_{1}$ with $m_{0}$ is interpreted as the mean or central frequency $f_{\text {mean }}$ of the signal in a chosen interval of frequencies, the mean length $\lambda_{\text {mean }}$ can be determined as:

$f_{\text {mean }}={ }^{m_{1}} / m_{0}$ and $\quad \lambda_{\text {mean }}={ }^{m_{0}} / m_{1}$

Physically, the mean frequency plays a role as a frequency centroid (spectral centre of gravity) of the one-sided power spectrum function (Michaelov et al. 1999). Thus, in the case of a single distinctive sharp maximum in the roughness spectrum (such as the one caused by a single dune generation), it can be used to assess the spatial distance between rhythmic bedforms, i.e. dune length. In the case of a real seabed, however, it is often observed that a dune height field with a particular spatial alignment may be narrowband at one location and broadband at another. Furthermore, primary (most energetic) bed surface roughness can be accompanied by secondary bedforms with the same alignment but different lengths. In such cases, the predominant mean frequency may shift and would not reflect dune length in the most reliable way.

On the other hand, in order to extract information about the characteristic dune length $\lambda_{\mathrm{ch}}$ in relation to the spectrum peak frequency, a weighted integral of power 4 was proposed by Young (1995) as a most reliable technique. This technique was subsequently applied by Davis et al. 
(2004), who studied small-scale wave-induced ripple spectral development. Therefore, in the present case of limited frequency range, the characteristic dune length can be expressed by:

$$
f_{\text {ch }}\left(\theta_{\mathrm{i}}\right)=\frac{\sum_{f_{\theta_{\mathrm{i}}}=f_{\text {thresh }}}^{F_{\mathrm{s}} / 2} f_{\theta_{\mathrm{i}}} S_{\theta_{\mathrm{i}}}^{4}\left(f_{\theta_{\mathrm{i}}}\right) \Delta f_{\theta_{\mathrm{i}}}}{\sum_{f_{\mathrm{\theta}_{\mathrm{i}}}=f_{\text {thresh }}}^{F_{\mathrm{s}} / 2} S_{\theta_{\mathrm{i}}}^{4}\left(f_{\theta_{\mathrm{i}}}\right) \Delta f_{\theta_{\mathrm{i}}}}
$$

and

$$
\lambda_{\mathrm{ch}}\left(\theta_{\mathrm{i}}\right)=\frac{1}{f_{\mathrm{ch}}\left(\theta_{\mathrm{i}}\right)}
$$

In addition, in direct analogy with the significant wave height concept first introduced by Sverdrup and Munk (1947) and widely used in sea surface wave theory (e.g. Goda 2010; Massel 2013), and also taking into
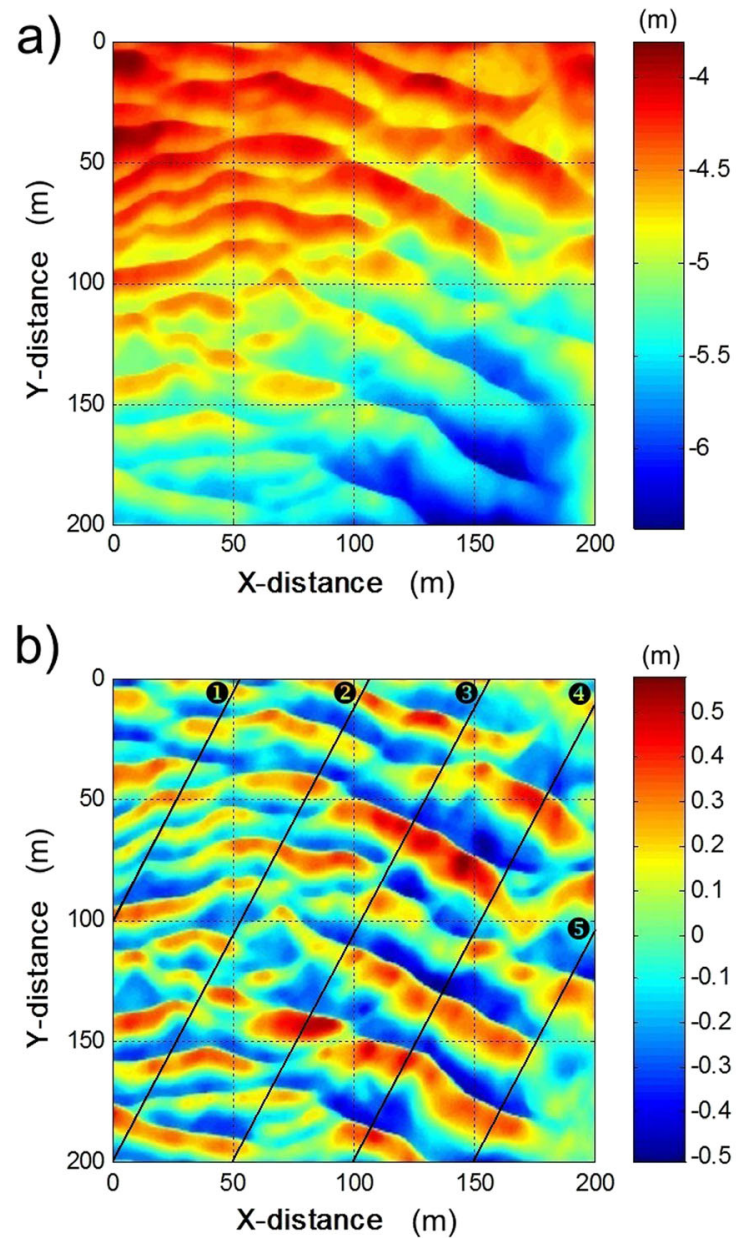

Fig. 3 a Depth field example (cf. yellow box in Fig. 9c and f) of one dominant dune generation in a $200 \times 200 \mathrm{~m}$ sub-domain. b Height field in the sub-domain after applying a detrending procedure. c Twodimensional normalized roughness spectrum estimated from the height account that the ratio of the peak-to-peak amplitude to the standard deviation for the sinusoidal wave is $2 \sqrt{2}$, the characteristic dune height can be estimated as:

$\eta_{\mathrm{ch}}\left(\theta_{\mathrm{i}}\right)=2 \sqrt{2} \cdot \sqrt{m_{0}\left(\theta_{\mathrm{i}}\right)}$

where $\eta_{\mathrm{ch}}\left(\theta_{\mathrm{i}}\right)$ is the characteristic dune height (in metres) for an appropriate spatial alignment angle $\theta_{\mathrm{i}}$, and $m_{0}\left(\theta_{\mathrm{i}}\right)$ is the zero moment of the spectral function (spectral energy) obtained by Eq. 7. It should be noted that the same multiplication coefficient was reported by Davis et al. (2004). They determined it by fitting a linear relationship between the characteristic ripple height and the variance of the ripple series for equilibrium rippled beds generated under irregular surface wave conditions within a wave flume. In the present study, two examples of $200 \times 200 \mathrm{~m}$ sub-domains consisting of dune structures with different scales of complexity were chosen and subjected to the analysis.

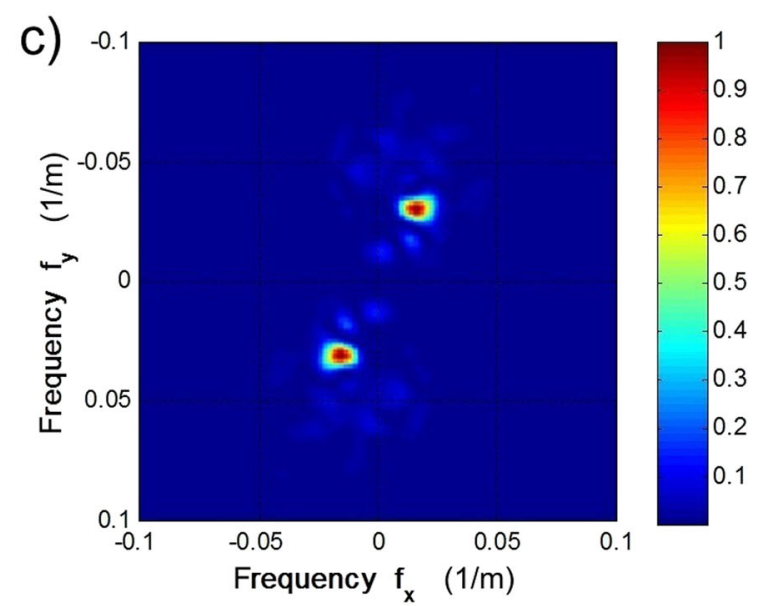

d)
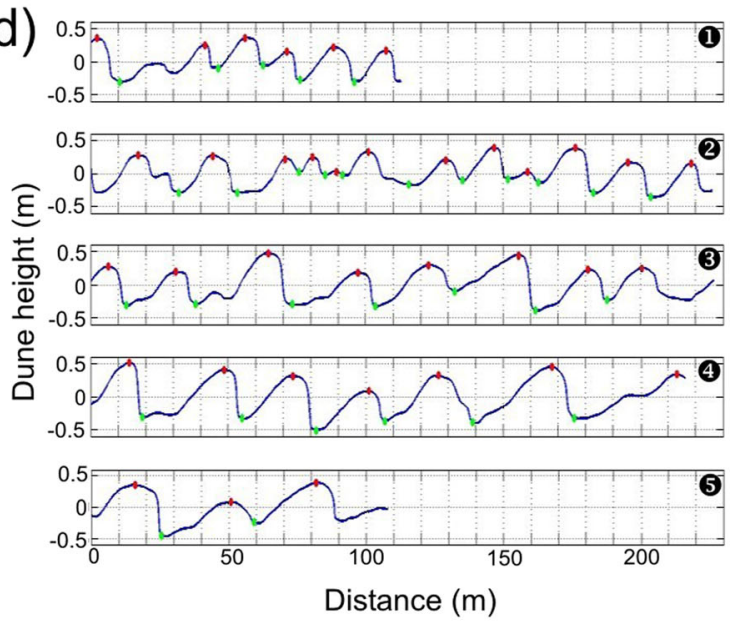

field. d Locations of crests and troughs (red and green respectively) identified using the zero-crossing technique for chosen transects shown in $\mathbf{b}$ (azimuth of transects $\theta=28^{\circ}$ relative to north) 
Fig. 4 Angular dependence of a the roughness spectrum energy $m_{0}\left(\mathrm{~m}^{2}\right)$ and $\mathbf{b}$ the second spectral moment $m_{2}$. Blue square Position of spectrum energy maximum, which determines the bedform crest primary alignment angle at $\theta_{\mathrm{pr}}=118^{\circ}$. Crest alignment angles are reported in degrees relative to north
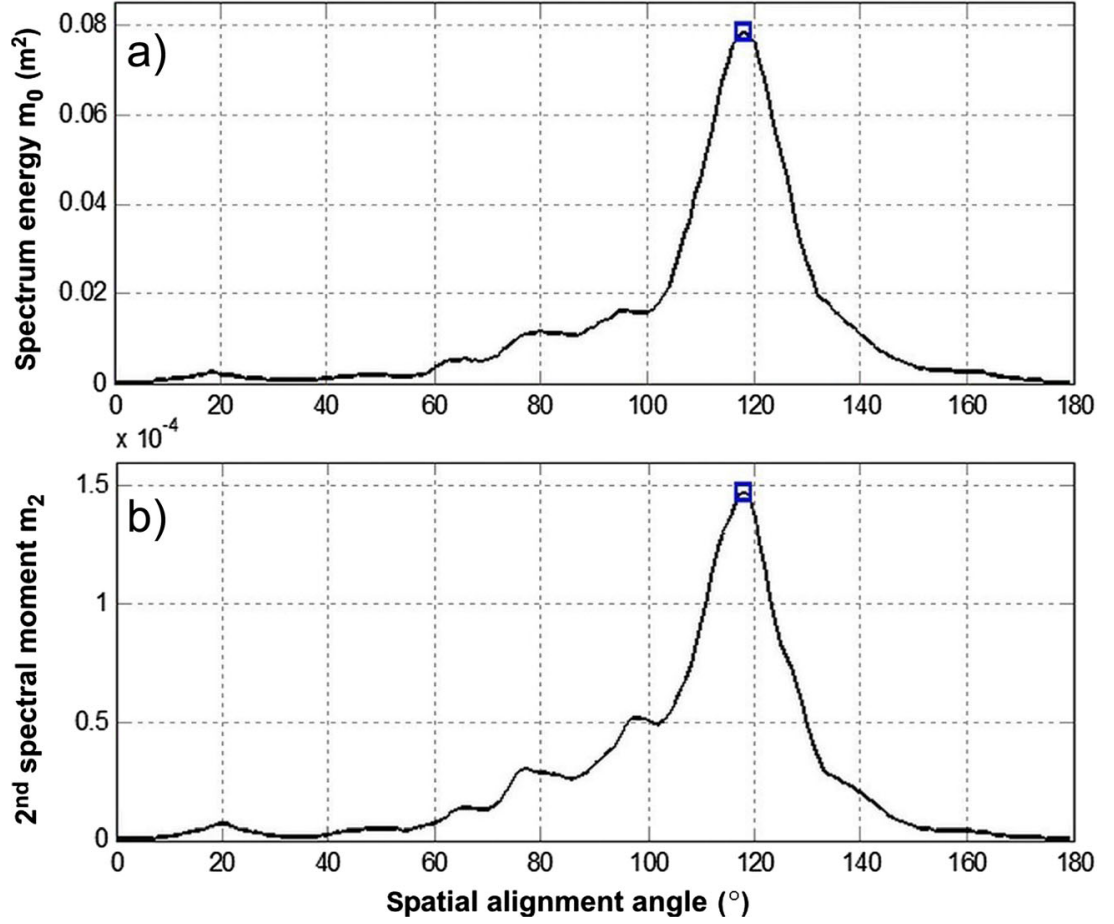

\section{Results}

\section{One dominating dune generation}

The height field of the original subset (Fig. 3a) was obtained after detrending (Fig. 3b), and its 2D spectrum was estimated using the DPSS two-dimensional taper function (Fig. 3c). This spectrum is anisotropic, exhibiting one individual highfrequency peak (mirrored) which is comprised of a diffuse cloud of cells with high power. The diffusive character of the peak can be explained by some variability of wavelengths and spatial alignment angles of observed (periodic) bedform structures, and is essentially always present in spectrums of real topographic data.

After extraction of a set of 180 one-dimensional "slices" from half of the 2D spectrum, the angular distribution of the roughness spectrum energy was obtained on the basis of Eq. 7 and is shown in Fig. 4a. The shape of the curve confirms the
Fig. 5 Slices of the 2D spectrum of Fig. 3c taken perpendicular (blue) and parallel (black) to bedform crests. Red dashed line Power-law fitting function with spectrum slope $\gamma=-4.2$. Green square and magenta rhombus Mean frequency $f_{\text {mean }}$ and characteristic frequency $f_{\text {ch }}$ calculated from Eqs. 8 and 9 respectively

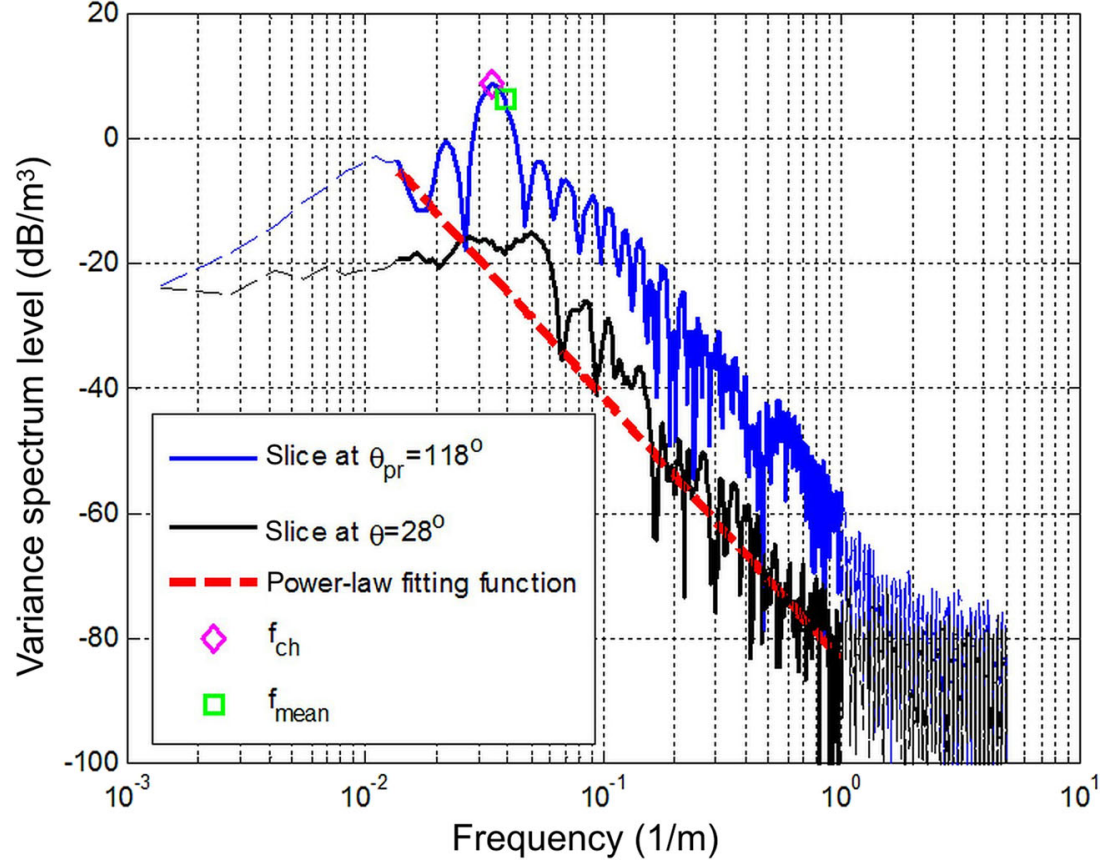


anisotropic nature of the bottom surface, and one individual high-energy peak can be easily distinguished which corresponds to the crests' primary spatial alignment angle at $\theta_{\mathrm{pr}}=118^{\circ}$ relative to north (blue square). The similar character of the second spectral moment $m_{2}$ curve (Fig. 4b) confirms that in this case the majority of energy is distributed along the obtained direction. Geometric variables of bedforms such as characteristic wavelength and height were determined on the basis of Eqs. 9 and 10. In this particular case for the crests' primary alignment angle at $\theta_{\mathrm{pr}}=118^{\circ}$, characteristic

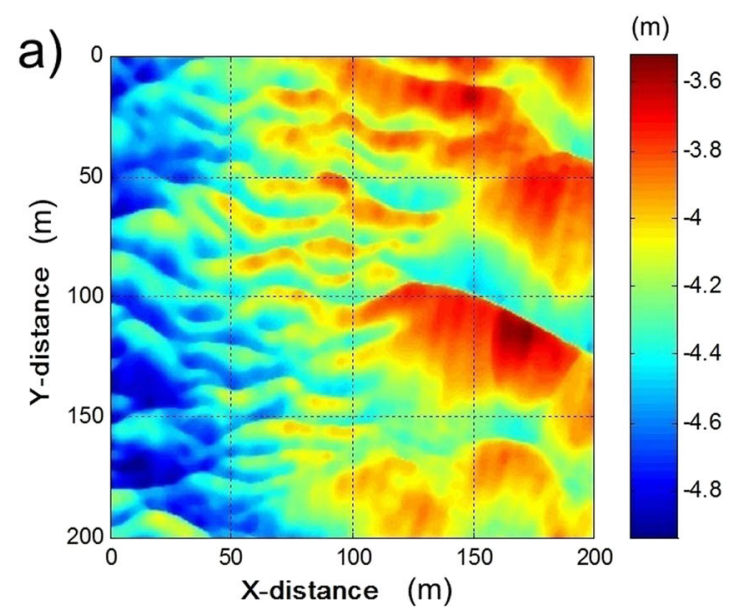

b)

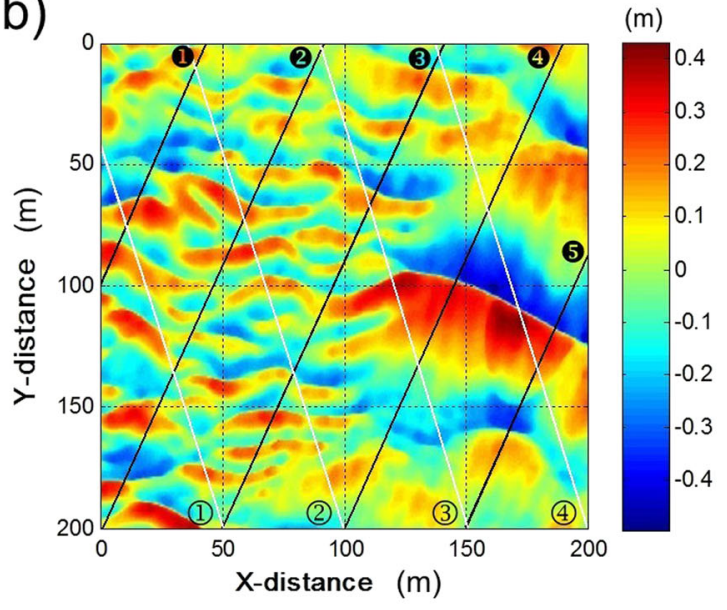

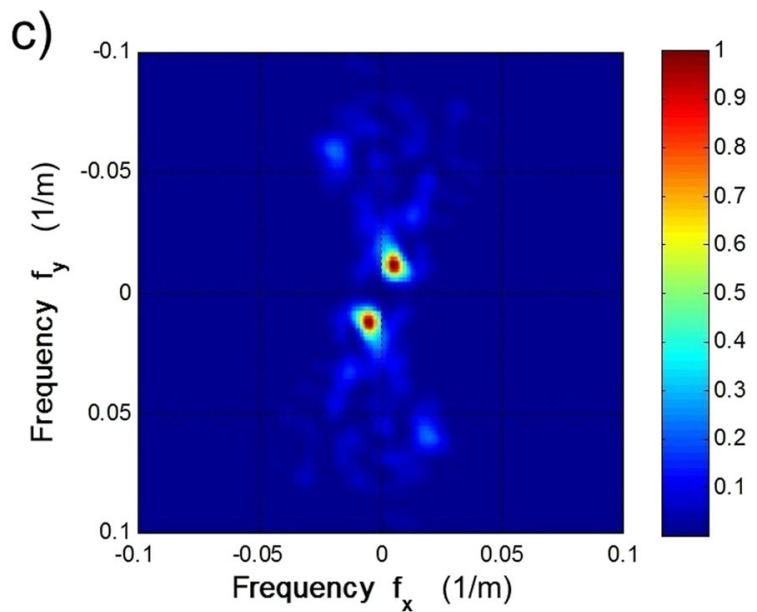

d)
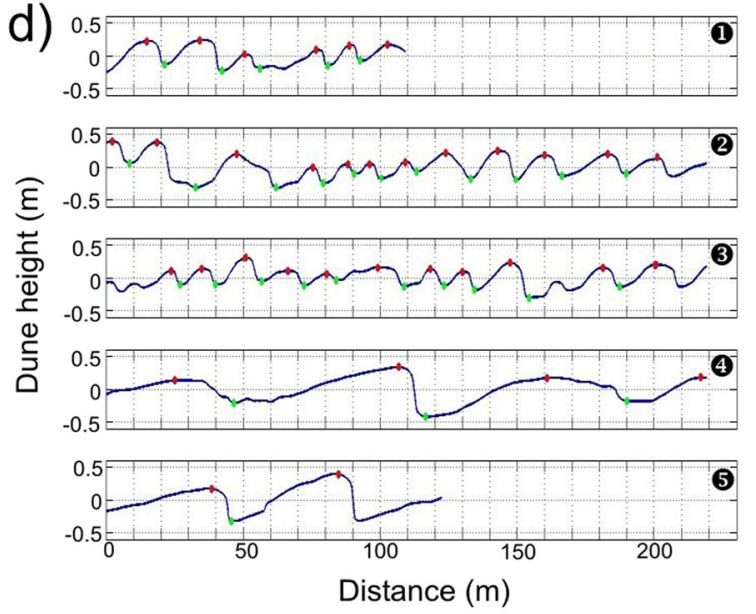

e)
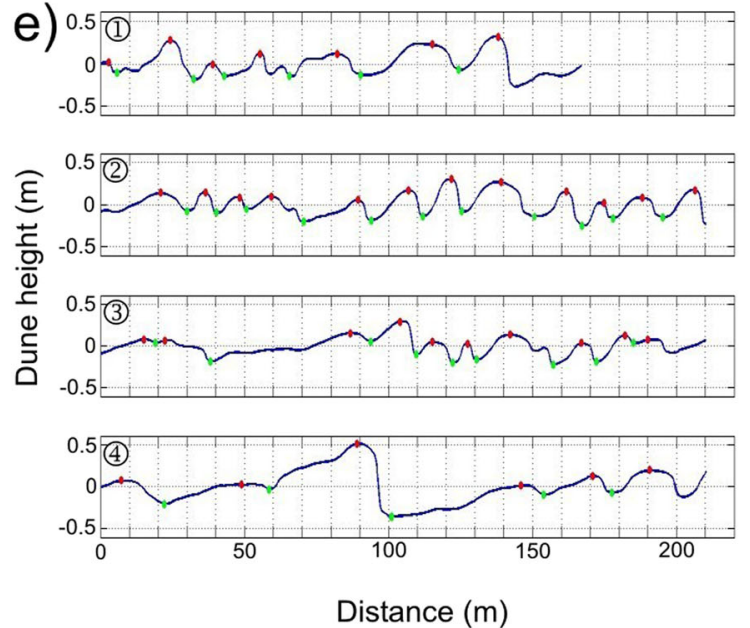

field. d, e Locations of crests (red) and troughs (green) identified using the zero-crossing technique for chosen transects shown in $\mathbf{b}$ in black and white (azimuth of transect $\theta_{1}=24^{\circ}$ and $\theta_{2}=342^{\circ}$ relative to north respectively) 
wavelength $\lambda_{\mathrm{ch}}\left(\theta_{\mathrm{pr}}\right)=28.8 \mathrm{~m}$ and height $\eta_{\mathrm{ch}}\left(\theta_{\mathrm{pr}}\right)=0.8 \mathrm{~m}$ were obtained.

An influence of rhythmic bedforms on the variance spectrum level is clearly seen in orthogonal slices (Fig. 5) of the two-dimensional spectrum taken perpendicular to the bedform crests (slice at $\theta_{\mathrm{pr}}=118^{\circ}$, blue curve) and parallel to them (slice at $\theta=28^{\circ}$, black curve). About $20 \mathrm{~dB}$ discrepancy between the orthogonal slices with a maximum difference of about $25 \mathrm{~dB}$ at the peak frequency is apparent in the frequency band from $f_{\text {thresh }}$ up to $f=1 \mathrm{~m}^{-1}$, i.e. between the "red" and "white" noise regions of the signal depicted in Fig. 5 by dashed curves. Additionally, for the slice taken perpendicular to the bedform crests, the mean frequency $f_{\text {mean }}$ and the characteristic frequency $f_{\text {ch }}$ calculated from Eqs. 8 and 9 are depicted in a green square and magenta rhombus respectively. It is clearly seen that the characteristic frequency $f_{\text {ch }}$ coincides exactly with a peak frequency in the spectrum (which is of particular interest), corresponding to the dominant space distance between crests $\left(\lambda_{\mathrm{ch}}\left(\theta_{\mathrm{pr}}\right)=28.8 \mathrm{~m}\right)$. The mean frequency $f_{\text {mean }}$ is only slightly shifted towards high frequencies by comparison to the peak frequency $f_{\text {ch }}$. This points to the predominance of only one (strong) frequency component in the spectrum, although it also confirms that, in the case of a real seabed, the mean frequency $f_{\text {mean }}$ does not reflect dune wavelength in the most reliable way.

\section{Two and more dune generations}

In the example from the south of the study area, a $200 \times 200 \mathrm{~m}$ sub-domain shows bedforms of various sizes. They are variously spaced and with crest-lines arranged in various directions (Fig. 6).

The shape of the spectrum energy curve (Fig. 7a) confirms the anisotropic nature of the bottom surface. Most of the energy concentrates in a wide range of alignment angles $\left(\sim 70-120^{\circ}\right)$ with a maximum which corresponds to the crests' primary spatial alignment angle at $\theta_{\mathrm{pr}}=114^{\circ}$ relative to north (blue square). In turn, analysis of the $m_{2}$ curve (Fig. 7b) reveals its maximum at $\theta_{\mathrm{sec}}=72^{\circ}$ (blue rhombus), from which it is possible to distinguish secondary bedforms arranged in this particular direction. The presence of secondary bedforms with a crest spatial alignment angle at $\theta_{\mathrm{sec}}=72^{\circ}$ is confirmed also by the occurrence of a local maximum with enough high spectrum energy (about $62.5 \%$ in comparison with the spectrum energy of the primary bedforms) at the same position (Fig. 7a). Note that the $m_{2}$ curve contains more distinct peaks which could be statistically analysed in order to find third and further generations of bedforms, a feature which could be of high significance in studies on dune dynamics.

The one-dimensional slices of the variance spectrum level for the obtained alignment angles with appropriate orthogonal slices are shown in Fig. 8. The spectra have distinct spectrum levels and slopes, which confirms the different character of bottom surface roughness in these particular directions. Thus, in this particular sub-domain, the characteristic wavelengths $\lambda_{\mathrm{ch}}\left(\theta_{\mathrm{pr}}\right)=69.4 \mathrm{~m}$ and $\lambda_{\mathrm{sec}}\left(\theta_{\mathrm{sec}}\right)=16.9 \mathrm{~m}$ as well as the characteristic heights $\eta_{\mathrm{ch}}\left(\theta_{\mathrm{pr}}\right)=0.42 \mathrm{~m}$ and $\eta_{\mathrm{ch}}\left(\theta_{\mathrm{sec}}\right)=0.33 \mathrm{~m}$ were obtained for the primary and secondary structures respectively.
Fig. 7 Angular dependence of a the roughness spectrum energy $m_{0}\left(\mathrm{~m}^{2}\right)$ and $\mathbf{b}$ the second spectral moment $m_{2}$. Positions of $m_{0}$ (blue square) and $\mathrm{m}_{2}$ maxima (blue rhombus) determine the bedform crest primary and secondary alignment angles at $\theta_{\mathrm{pr}}=114^{\circ}$ and $\theta_{\mathrm{sec}}=72^{\circ}$ respectively. Crest alignment angles are reported in degrees relative to north
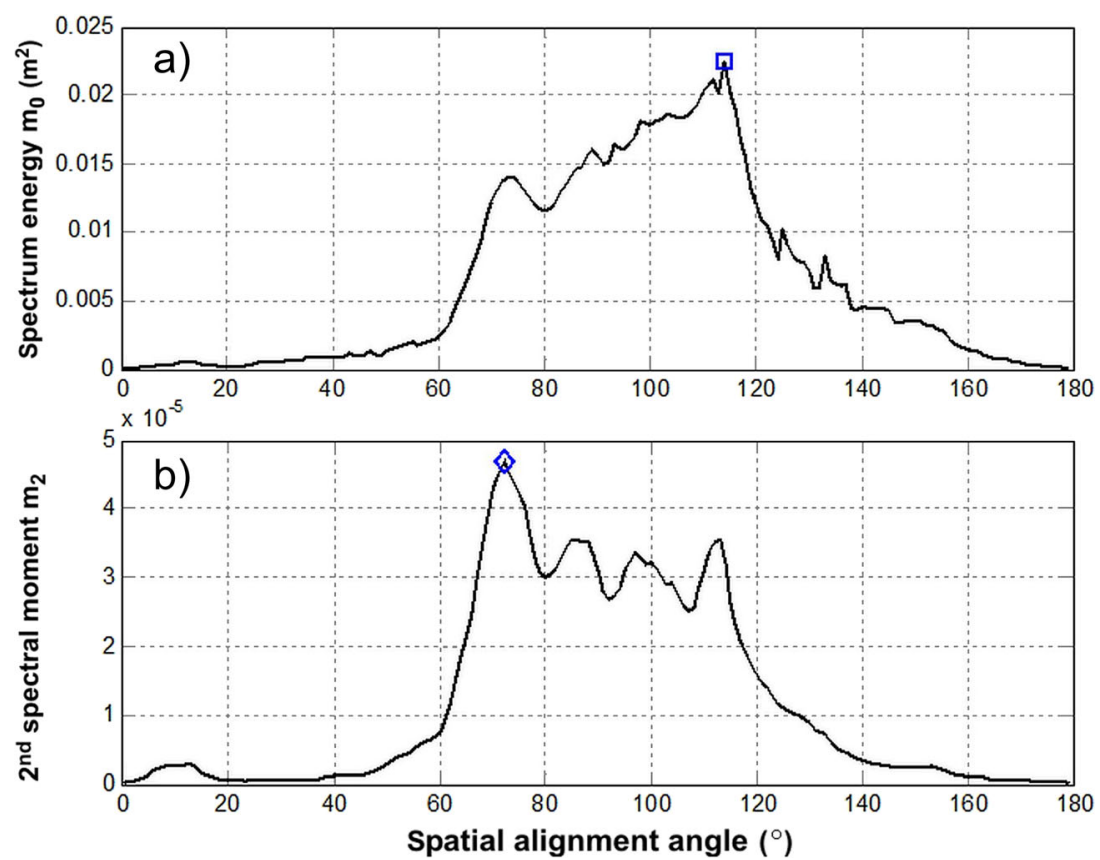


\section{Morphology of Vistula River mouth}

The present bathymetric data confirm earlier findings of Staśkiewicz et al. (2010) — the bottom relief of the coastal sector of the Vistula River mouth is characterised by a sandbar along the western bank of the river and a deep trough along the eastern bank. The sandbar elevated above the $-4 \mathrm{~m}$ isoline is elongated towards the middle of the river valley in the most upstream sector of the study area. There is another shoal shallower than $-4 \mathrm{~m}$ in the middle of the channel in the most northern sector. It breaches the water surface in the north as islands visible in aerial photographs (Fig. 1c). The deepest trough bottom reaches below $-7 \mathrm{~m}$.

The entire investigated riverine bed is covered by multiple generations (groups) of small to large dunes (as in Ashley 1990). The dunes have both two- and three-dimensional shapes of various orientations (Fig. 9), with asymmetries indicating their general seaward migration (Figs. 3d, 6d, e). The applied method of analysis in sub-domains reveals a consistent pattern of the primary-generation bedforms. The longest dunes $(\sim 70 \mathrm{~m})$ are located in the south and in the trough along the eastern bank (see Fig. 9a), and they are mostly oriented towards the northeast (Fig. 9c). In the centre of the study area, dunes shorter than $20 \mathrm{~m}$ (Fig. 9a) and lower than $0.5 \mathrm{~m}$ (Fig. 9b) are dominant. These are mostly oriented northwards (Fig. 9c). The highest dunes (up to $1.2 \mathrm{~m}$ ) are situated in the northern part of the river mouth, where the crests are orientated towards the depressions between shoals to the NE and NW, forming a V pattern (Fig. 9c). The second generation of bedforms was identified for 107 sub-domains. Surprisingly, a broad range of sizes was calculated with several exceeding $60 \mathrm{~m}$ in length (Fig. 9d) and $0.8 \mathrm{~m}$ in height (Fig. 9e). The majority, however, are shorter than $30 \mathrm{~m}$ and lower than 0.4 $\mathrm{m}$. The analysis of their orientation (Fig. 9f) reveals significant differences with respect to dunes of the first generation. Especially in the south where the shoal reaches the middle of the river, one can trace a vector splitting of the generations with primary dunes overflowing the shoal towards the NE and secondary bedforms continuing northwards along the western bank of the Vistula River mouth.

\section{Discussion}

\section{Method performance}

In order to statistically validate geometric bedform variables obtained by the spectral method, a set of parallel onedimensional transects with $1 \mathrm{~m}$ steps were generated perpendicular to the primary bedform alignment angle $\theta_{\mathrm{pr}}$ (in the example with one dominant bedform direction; Fig. 3, yellow box in Fig. 9c). Two hundred bedform elevation profiles were derived along the transects (with azimuth $\theta=28^{\circ}$ derived in the course of method application) from the depth field (Fig. 3a),
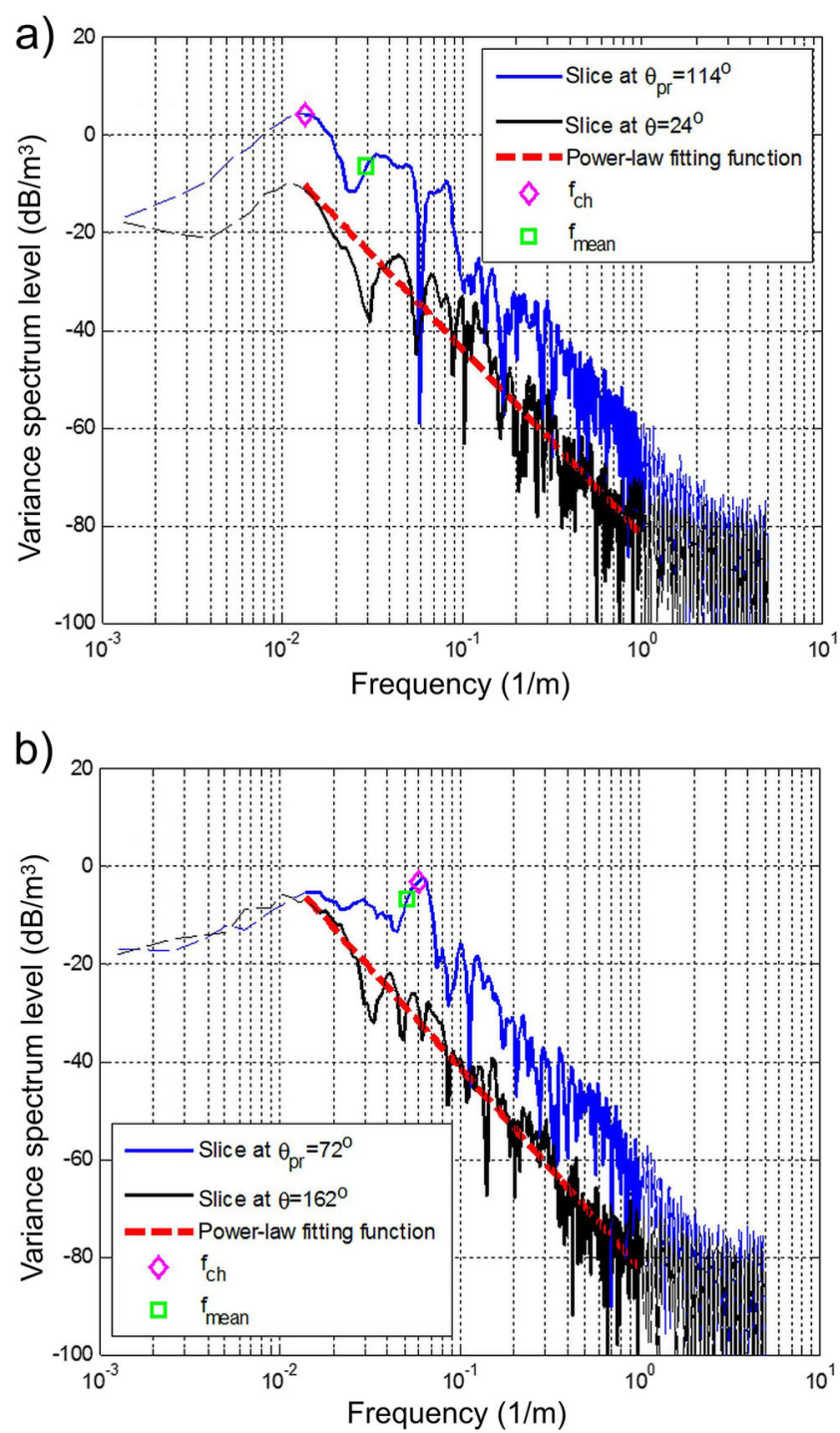

Fig. 8 Slices of the 2D spectrum of Fig. 6c taken perpendicular (blue) and parallel (black) to the dune crest a primary $\theta_{\mathrm{pr}}=114^{\circ}$ and $\mathbf{b}$ secondary $\theta_{\text {sec }}=72^{\circ}$ spatial alignment angles. Red dashed lines Power-law fitting functions with spectrum slopes $\gamma=-3.8$ and -4.0 respectively. Green square and magenta rhombus Mean frequency $f_{\text {mean }}$ and characteristic frequency $f_{\text {ch }}$ calculated based on Eqs. 8 and 9 respectively

and were analysed based on the approach presented in Van der Mark and Blom (2007), which is able to determine crest and trough positions of individual bedforms. Next, histograms of bedform height (defined as the vertical distance between a

Fig. 9 Results of proposed semi-automated method applied for the bathymetry of the Vistula River mouth: primary generation of a dune lengths, $\mathbf{b}$ dune heights and $\mathbf{c}$ dune orientations calculated in 331 test fields throughout the domain, and secondary generation of $\mathbf{d}$ dune lengths, $\mathbf{e}$ dune heights and $\mathbf{f}$ dune orientations calculated in the same test fields. Note that $\mathbf{d}-\mathbf{f}$ contain only fields where calculations of the second generation were conclusive. Each $50 \times 50 \mathrm{~m}$ box represents the centre of a $200 \times 200 \mathrm{~m}$ field overlapping $75 \%$ with neighbouring boxes. Yellow and orange boxes in $\boldsymbol{c}$ and $\boldsymbol{f}$ Test fields shown in detail in Figs. 3 and 6 respectively. Coordinates in Polish national geodetic coordinate system PUWG1992 


\section{FIRST GENERATION}
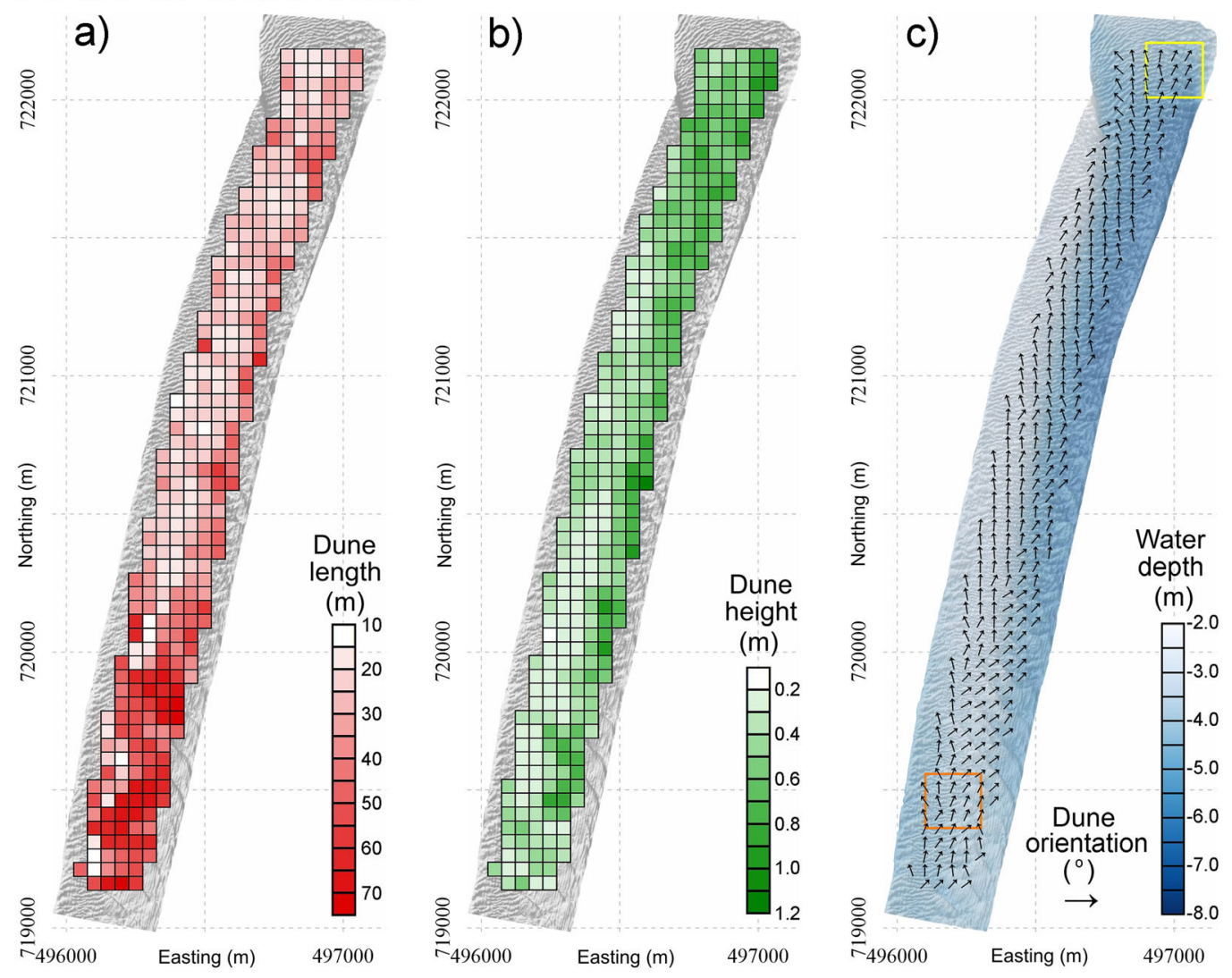

\section{SECOND GENERATION}
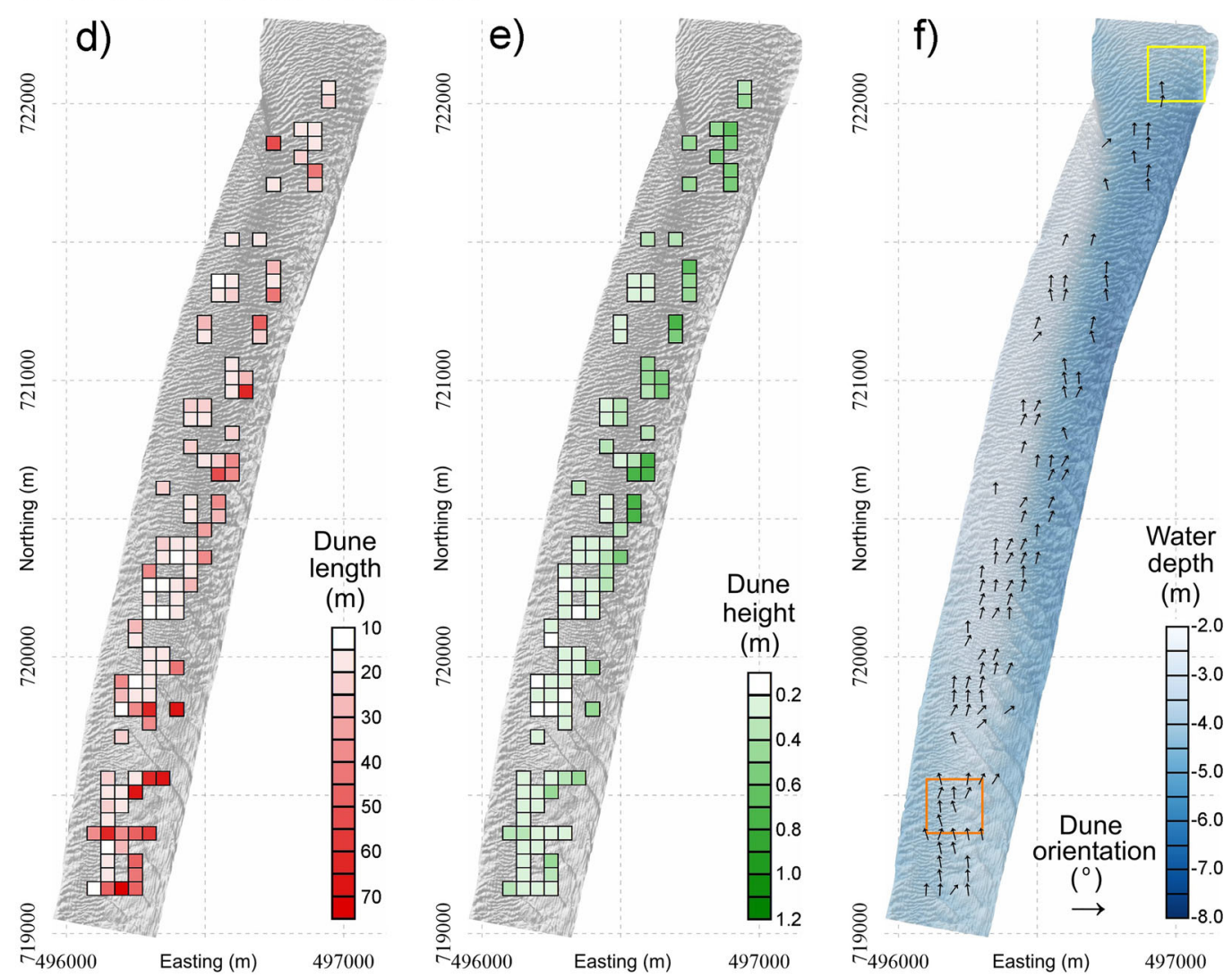
crest and its downstream trough, Fig. 10a) and bedform length (defined as the horizontal distance between two subsequent crests, Fig. 10b) were obtained.

The most suitable probability density functions (with the smallest error estimated based on Eq. 1 in Van der Mark et al. 2008) were fitted to the appropriate geometric variables distributions. Thus, it was found that the Weibull and Gamma distributions yield the best approximation for bedform height and wavelength respectively, in agreement with the results of Van der Mark et al. (2008). In addition, the significant bedform height was calculated as the mean wave height value of the highest third of the waves, and $H_{\mathrm{s}}=0.65 \mathrm{~m}$ was obtained.

Conducting a direct analogy with the significant wave height concept widely used within sea surface wave theory, the characteristic bedform height $\eta_{\mathrm{ch}}$ can also be estimated from the zero spectral moment (spectral analysis gives an energy-based significant wave height, Eq. 10). However, it should be noted here that, based on the results obtained by the spectral method proposed herein and the traditional statistical approach, the characteristic height $\eta_{\mathrm{ch}}$ of $0.8 \mathrm{~m}$ seems to be overestimated in comparison with the significant bedform height $H_{\mathrm{s}}$ of $0.65 \mathrm{~m}$. The hypothetical assumption that bedforms were approximated as symmetrical sinusoidal waves (multiplication coefficient $2 \sqrt{2}$ in Eq. 10), which is rarely the case for real seabed roughness, may partly explain this overestimation. Conversely, Van der Mark et al. (2008)
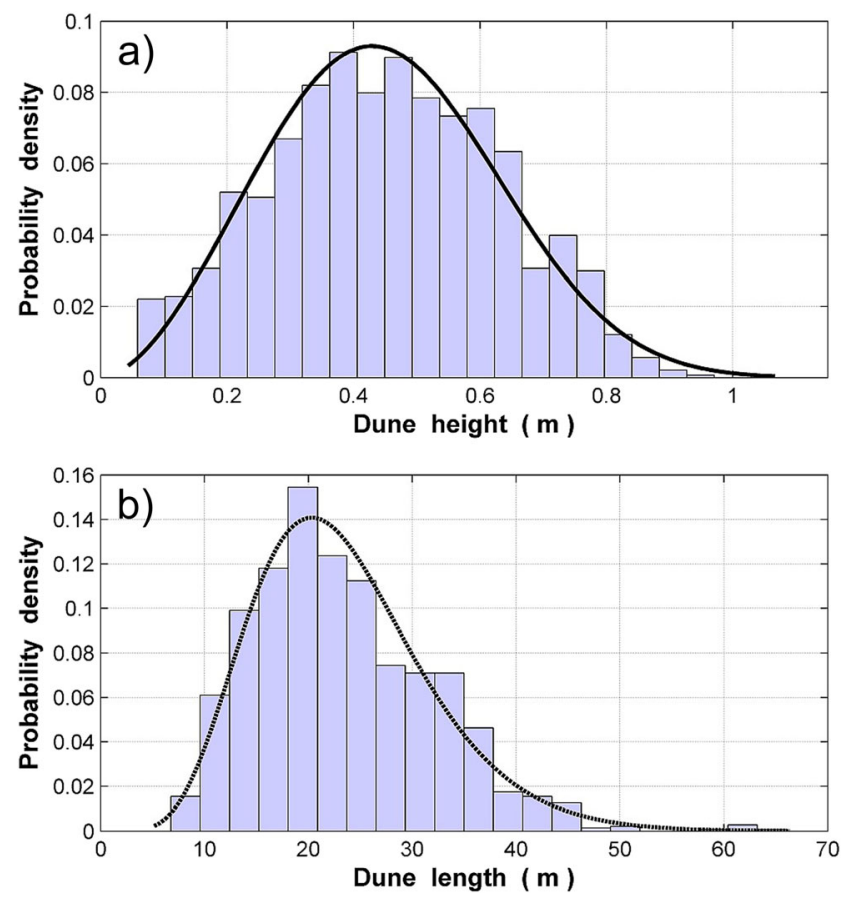

Fig. 10 Histograms of a dune height and $\mathbf{b}$ dune length calculated in the sub-domain shown in Fig. 3 with Weibull and Gamma probability density functions respectively showed that, if the ratio of river width $W$ to hydraulic radius $R$ is larger than approximately 10 (in the case of the Vistula River mouth, $W / R>>10$ ), a linear relation exists between the standard deviation and mean value of bedform height and, for field conditions, a constant coefficient of variation $C_{\Delta}=\sigma / \mu=0.47$ can be applied. Considering the above, the result obtained here is in reliable agreement with the conclusions of Van der Mark et al. (2008).

Application of the same validation technique to the sub-domain containing two obvious generations of dunes (Fig. 6) reveals that the analysis of bedform dimensions of various sizes is not straightforward, but again reliable results were achieved. Along each of the two azimuths derived in the course of method application $\left(\theta_{1}=24^{\circ}\right.$ and $\theta_{2}=342^{\circ}$, i.e. perpendicularly to the obtained $\theta_{\mathrm{pr}}=114^{\circ}$ and $\theta_{\mathrm{sec}}=72^{\circ}$ respectively), over 200 profiles were subjected to the Van der Mark and Blom (2007) method of automatic recognition of crests and troughs of various dunes. Along the primary azimuth $\theta_{1}=24^{\circ}$, the mean and median values of the dune lengths and heights $\left(\lambda_{\text {mean }}\left(\theta_{1}\right)=26.3 \mathrm{~m}, \eta_{\text {mean }}\left(\theta_{1}\right)=0.32 \mathrm{~m} ; \lambda_{\text {median }}\left(\theta_{1}\right)=20.8 \mathrm{~m}\right.$, $\left.\eta_{\text {median }}\left(\theta_{1}\right)=0.30 \mathrm{~m}\right)$ as well as the significant bedform height $H_{\mathrm{s}}\left(\theta_{1}\right)=0.48 \mathrm{~m}$ were derived from the statistics (Fig. 11a, b). In the course of applying the proposed spectral method, the characteristic dune length $\lambda_{\mathrm{ch}}\left(\theta_{\mathrm{pr}}\right)=69.4 \mathrm{~m}$ and characteristic dune height $\eta_{\mathrm{ch}}\left(\theta_{\mathrm{pr}}\right)=0.42 \mathrm{~m}$ were obtained. Both of the achieved values seem to be overestimated with respect to the mean statistics behind the zero-crossing technique, although the significant bedform height and characteristic dune height values are well comparable. On the other hand, along the secondary azimuth $\theta_{2}=342^{\circ}$, both the achieved values from the spectral method $\left(\lambda_{\mathrm{ch}}\left(\theta_{\mathrm{sec}}\right)=16.9 \mathrm{~m}\right.$ and $\left.\eta_{\mathrm{ch}}\left(\theta_{\mathrm{sec}}\right)=0.33 \mathrm{~m}\right)$ are comparable with the values obtained from the statistics $\left(\lambda_{\text {mean }}\left(\theta_{2}\right)=20.2 \mathrm{~m}, \eta_{\text {mean }}\left(\theta_{2}\right)=0.28 \mathrm{~m} ; \lambda_{\text {median }}\left(\theta_{2}\right)=17.0 \mathrm{~m}\right.$, $\left.\eta_{\text {median }}\left(\theta_{2}\right)=0.26 \mathrm{~m}\right)$, although an underestimation of the "spectral" characteristic dune height $\eta_{\mathrm{ch}}\left(\theta_{\mathrm{sec}}\right)$ in comparison with the "statistical" significant wave height $H_{\mathrm{s}}\left(\theta_{2}\right)=0.45 \mathrm{~m}$ is observed (Fig. $11 \mathrm{c}$, d). The scatter of the measured geometric values obtained by both methods can be explained by the fact that, using the proposed spectral approach, only the most energetic bedforms are selected for analysis as the primary generation of dunes and second-most energetic (secondary) generation, whereas the entire sub-domain is analysed here using the method proposed by Van der Mark and Blom (2007). In the latter, information on both generations of dunes (primary and secondary) is included simultaneously in the statistics. So, the influence of one dune generation on another one, and vice versa, can contribute to the uncertainties in measured geometric values obtained by the statistical approach. For example, it is clearly visible as the presence 

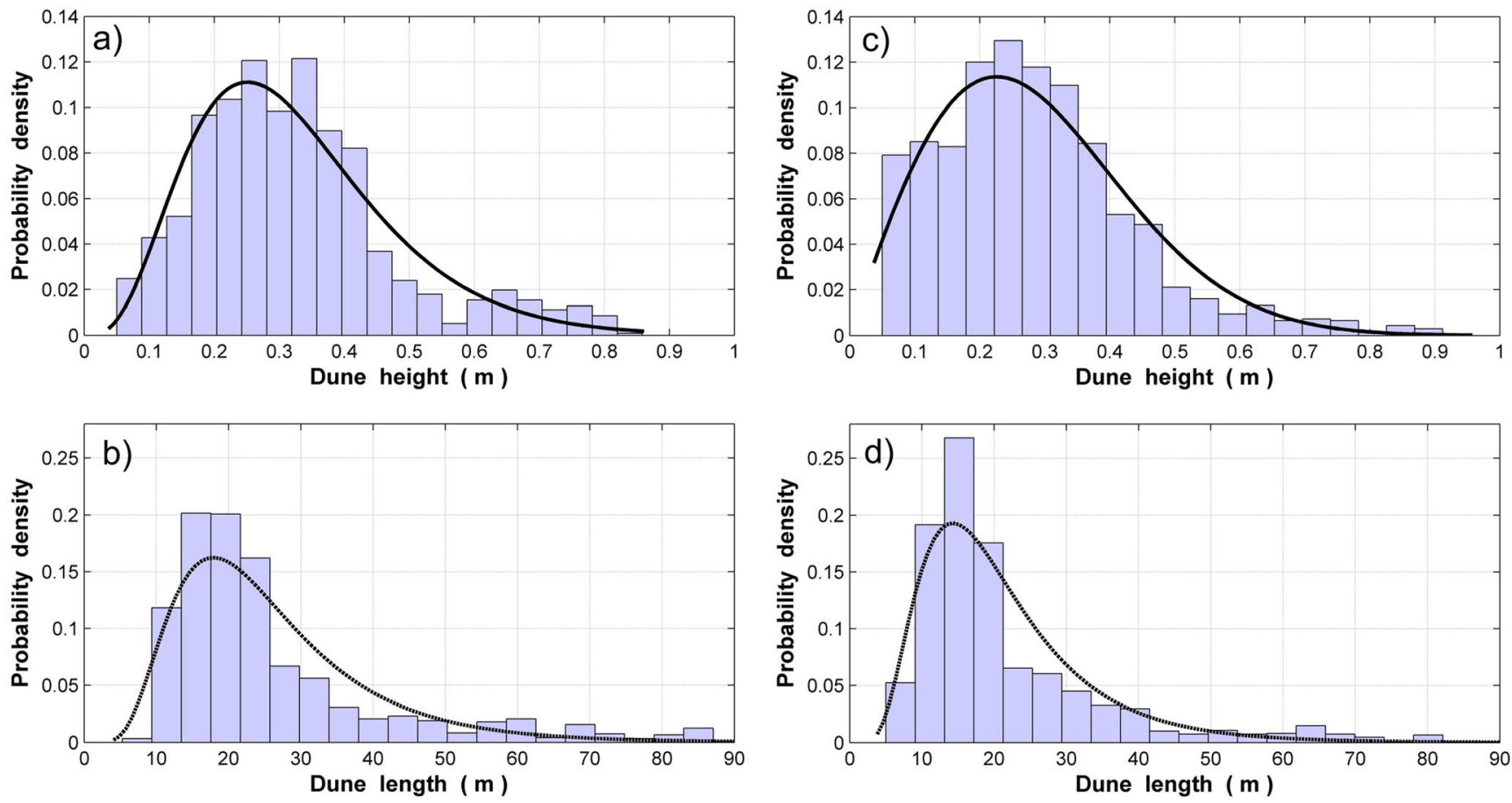

Fig. 11 Histograms of a, $\mathbf{c}$ dune height with Gamma and Weibull probability density functions respectively, and $\mathbf{b}$, $\mathbf{d}$ dune length with log-normal probability density functions calculated in the sub-domain

shown in Fig. 6 for primary and secondary dune generations with spatial alignment angles $\theta_{\mathrm{pr}}=114^{\circ}$ and $\theta_{\mathrm{sec}}=72^{\circ}$ respectively

of long tails in the histograms of dune heights and lengths (Fig. 11c, d), although there are no such high and long dunes in this particular generation of dunes, i.e. in the group of dunes with the orientation angle $\theta_{\mathrm{sec}}=72^{\circ}$ (Fig. 6). Confirmation that both generations of dunes are calculated twice along various azimuths can be found also in Fig. 6d (cross-sections nos. 4 and 5) and Fig. 6e (crosssection no. 4; see bed elevation profiles and positions of crests and troughs of the largest dunes in the chosen subdomain).

Generally, the most appropriate azimuth for extracting one-dimensional cross-sections from bathymetric surfaces is a priori unknown, so that application of the zero-crossing method can give even larger differences when analysing domains of more complicated shape than a canalized river. Although the zero-crossing method seems to be irreplaceable in determining the locations of crest and trough points and then the geometric properties of individual bedforms, it can fail in an environment of multiple generations of dunes. By contrast, application of the proposed procedure allows to identify and parameterise various generations of rhythmic bedforms more efficiently.

\section{Morphodynamics of Vistula River mouth}

Discharge values of the Vistula River recorded in Tczew suggest that there existed a certain bimodality of the riverine

regime during 18 months before the present measuring campaign. Hydrological forces acting during the most common dry period of low discharge of $700 \mathrm{~m}^{3} / \mathrm{s}$ and less should produce smaller bedforms than discharge higher than $1,100 \mathrm{~m}^{3} / \mathrm{s}$ related to spring snow melt and precipitation floods. In May and the first days of June 2012 shortly prior to the present bathymetric measurements, the discharge only twice exceeded $1,000 \mathrm{~m}^{3} / \mathrm{s}$ (in toto for $28 \mathrm{~h}, 4 \%$ of all records), whereas in March and April it was generally higher than $1,200 \mathrm{~m}^{3} / \mathrm{s}(80 \%$ of records, Fig. 2a). This suggests that supposedly larger bedforms produced in April were not entirely washed out in the next 2 months.

The scatter plot of dune lengths vs. heights, however, reveals no distinct groups marking the two dune generations identified by the proposed method (Fig. 12). There exists a certain group of secondary bedforms (Fig. 12, in blue) smaller than $20 \mathrm{~m}$ in length and $0.5 \mathrm{~m}$ in height which could act as representative of low Vistula discharge, but the same sizes are found frequently as the first generation (Fig. 12, in yellow) in other sub-domains throughout the study area. Similarly, the largest dunes (longer than $60 \mathrm{~m}$ ) can be found sometimes as secondary generations, although mostly they belong to the first generation and are probably related with high Vistula discharges.

With respect to the global mean trend of Flemming (1988), the bedforms of the Vistula River mouth fall below the average relationship between dune length and height (Fig. 12). If one assumes that the mean 


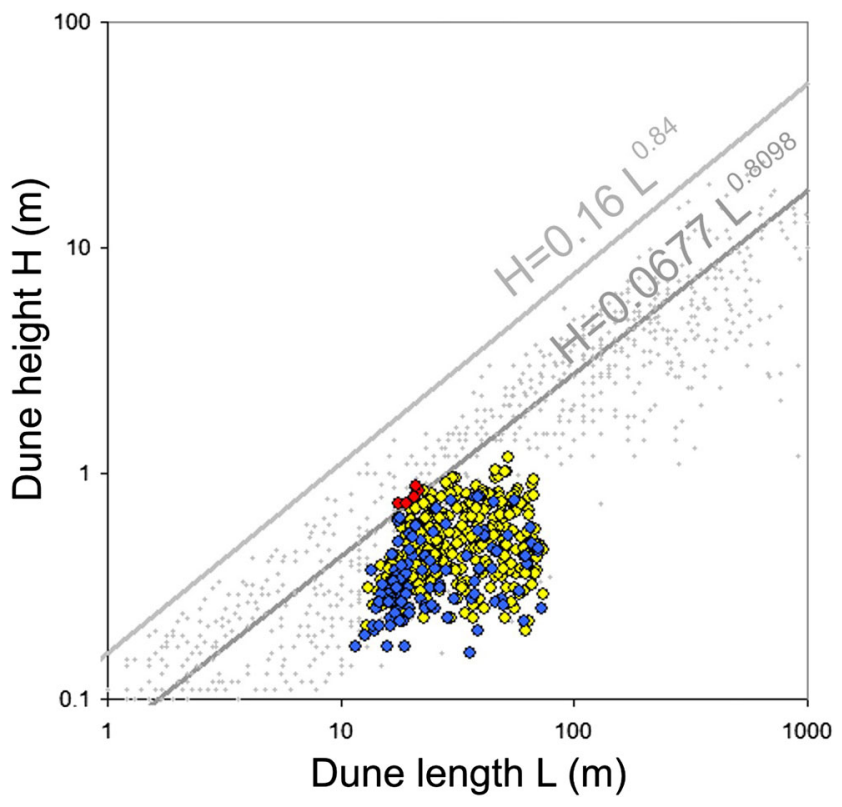

Fig. 12 Plot of dune length vs. dune height overlapping the world dataset summarised by Flemming (1988, grey dots). Each circle represents the result of application of the proposed method to one $200 \times 200 \mathrm{~m}$ square. Yellow circles Primary dune generations, blue circles secondary generations. Red Steepest dunes exceeding the average world relationship $H=0.0677 L^{0.8098}$

global trend reflects dunes which stay in equilibrium with the driving force of flow, one concludes that the bedforms of the Vistula River mouth are underdeveloped. This suggests that the dunes may be sedimentstarved due to a lack of material for constructing fully developed dune bodies under peak velocities, or that peak velocities occur for too short a time to be able to amass the dune body and reach equilibrium. There are, however, five exceptions concerning the steepest dunes in the study area (Fig. 12, in red), which evidently reached their equilibrium form.

The sub-domains containing these dunes are located in the most northern part of the river mouth (black boxes in Fig. 13). The analysis of dune orientation shows that this is where the dunes migrating in the eastern trough meet the dunes crossing the shoal in the west. Such a convergence area suggests that the general bottom morphology of the river mouth splits the water flow into two streams which converge in the north, a situation in which peak velocities large enough to form fully developed dunes can occur. In the south (at the Northing coordinate below $\sim 719500 \mathrm{~m}$ ), on the other hand, an area of dune divergence was identified. The largest dunes in the area of the first generation are clearly crossing the central shoal towards the eastern trough, which suggests that this is the path of strongest currents. Smaller dunes continue towards the western bank along the shoal, and this stream converges with

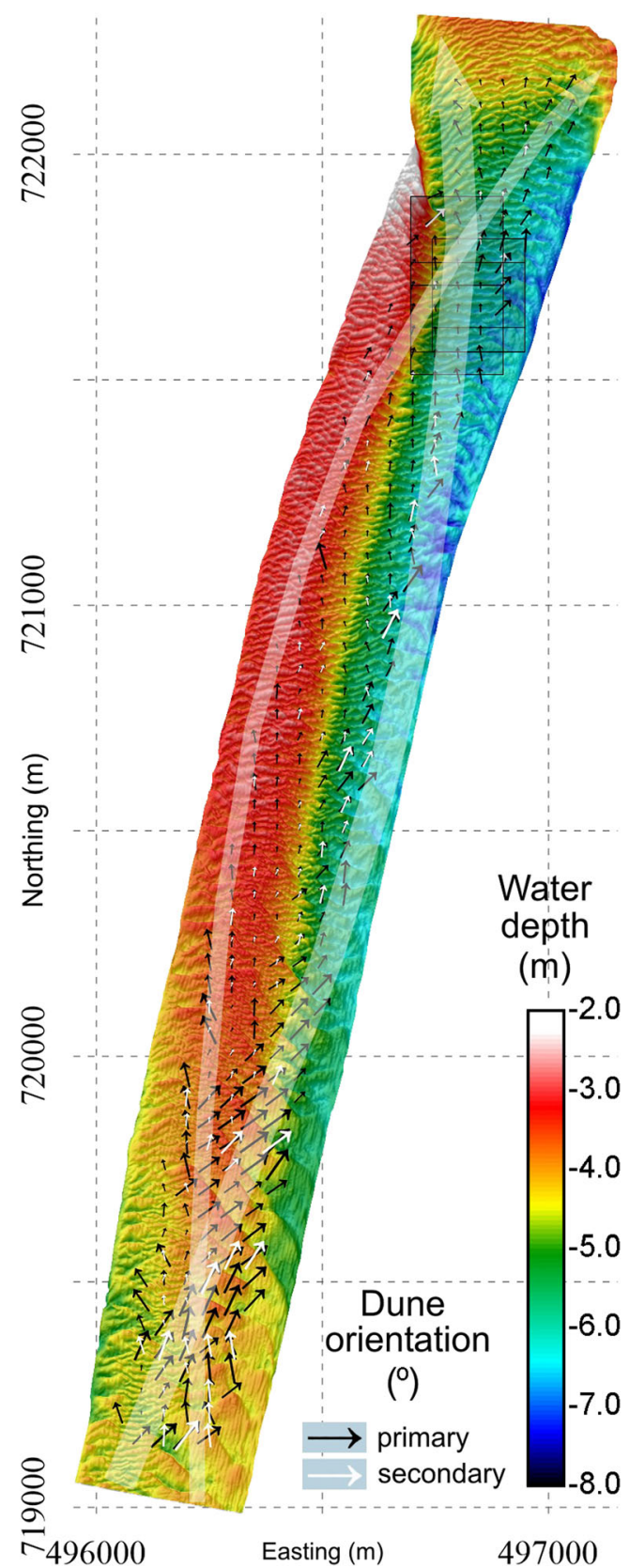

Fig. 13 Interpreted paths of primary (thick white semi-transparent arrow) and secondary (thin white semi-transparent arrow) bedforms migrating through the investigated sector of the Vistula River mouth. The size of arrows of dune orientation is proportional to dune length. Black squares Sub-domains with steepest dunes (marked in red in Fig. 12)

the main one in the north. The two probable streams identified from bedform orientations are shown by white semi-transparent arrows in Fig. 13.

\section{Conclusions}

The new method for spectral analysis of seabed topographic roughness based on the 2D Fourier transform technique is 
applied to characterise the bedforms of the Vistula River mouth. The method involves the extraction of a set of onedimensional slices from the 2D power spectrum and the calculation of low-order spectral moments. The main conclusions are:

- The approach enables the quantification of bedform parameters such as spatial alignment, length and height, also providing the possibility of describing multiple generations of undulating bedform structures without applying any band-pass filtering.

- By calculating the zero spectral moment $m_{0}$ (Eq. 5), which plays the role of spectrum energy, it is possible to obtain the roughness spectrum energy angular distribution and determine the space alignment angle of primary bedforms (most energetic). Distinguishing secondary bedforms is possible on the basis of analysis of the second spectral moment $m_{2}$ (Eq. 6) angular distribution.

- In the case of a real seabed, the mean frequency $f_{\text {mean }}$, defined as the ratio of the first spectral moment to the zero one (Eq. 8), is not a suitable parameter to obtain information about the dominant bedform length. In relation to the determination of the spectrum peak frequency, which is of more interest, the characteristic frequency $f_{\mathrm{ch}}$ (Eq. 9), defined by using a weighted integral of power 4 of the spectral function proposed by Young (1995), seems to be the most reliable approach.

- The overall result of "scanning" the study area automatically in 331 pre-designed $200 \times 200 \mathrm{~m}$ sub-domains shows the complex character of the Vistula River mouth bed covered by dunes with distinct crest-line alignments, lengths and heights, highlighting the diversity of bedform geometric dimensions from one sub-domain to the other. The analysis revealed two distinct paths of two dune generations. The largest dunes (at least $70 \mathrm{~m}$ in length and 1 $\mathrm{m}$ in height) are migrating north along the deeper eastern bank, whereas smaller bedforms (less than $20 \mathrm{~m}$ long and $0.5 \mathrm{~m}$ high) migrate along the shoal and western bank. Moreover, areas of dune divergence in the south and dune convergence in the north parts of the Vistula River mouth were identified.

- The approach considers only periodic bottom structures with space frequency components which fall within a limited frequency range. A choice of cut-off low-frequency $f_{\text {thresh }}$ (Eq. 7) in order to filter the "red noise" frequency components out of the spectrum was a compromise between the size of the analysed sub-domains $(200 \times 200 \mathrm{~m})$ and minimization of crest-line alignment and length uncertainties (see Cazenave et al. 2013), and was to a certain extent arbitrary. In order to describe large datasets on rhythmic seabed surface roughness in a fully automated way, an improved method which considers the presence of bedforms with larger lengths is required.
- The method requires high-precision bathymetry and as a result provides a quick and efficient tool for estimating topographic roughness, vital especially for constructing numerical models of hydrology and sediment transport.

Acknowledgements The authors are grateful to the National Centre for Research and Development (Poland) for funding this work by grant VISTULA No PBS1/A2/3/2012. We wish to thank to scientists of the Department of Operational Oceanography of the Maritime Institute in Gdańsk for their help in preparing and carrying out the bathymetric survey. The authors would like to express their gratitude to Pierre W. Cazenave, one anonymous reviewer and the journal editors for their constructive criticism and valuable comments.

\section{Compliance with ethical standards}

Conflict of interest The authors declare that there is no conflict of interest with third parties.

Open Access This article is distributed under the terms of the Creative Commons Attribution 4.0 International License (http:// creativecommons.org/licenses/by/4.0/), which permits unrestricted use, distribution, and reproduction in any medium, provided you give appropriate credit to the original author(s) and the source, provide a link to the Creative Commons license, and indicate if changes were made.

\section{References}

Akal T, Hovem J (1978) Two-dimensional space series analysis for seafloor roughness. Mar Geotechnol 3:171-182

Allen JRL (1982) Sedimentary structures: their character and physical basis. Elsevier, New York

Ashley GM (1990) Classification of large-scale subaqueous bedforms: a new look at an old problem. J Sediment Res 60:160-172. doi:10.2110/jsr.60.160

Augustowski B (1982) The valley of the lower Vistula (in Polish). Ossolineum, Wroclaw

Barnard PL, Erikson LH, Kvitek RG (2011) Small-scale sediment transport patterns and bedform morphodynamics: new insights from high-resolution multibeam bathymetry. Geo-Mar Lett 31:227-236. doi:10.1007/s00367-011-0227-1

Bartholdy J, Flemming BW, Ernstsen VB, Winter C, Bartholomä A (2010) Hydraulic roughness over simple subaqueous dunes. GeoMar Lett 30:63-76. doi:10.1007/s00367-009-0153-7

Bartholomä A, Ernstsen VB, Flemming BW, Bartholdy J (2004) Bedform dynamics and net sediment transport paths over a flood-ebb tidal cycle in the Grådyb channel (Denmark), determined by highresolution multibeam echosounding. Danish J Geogr 104:45-55. doi:10.1080/00167223.2004.10649503

Best J (2005) The fluid dynamics of river dunes: a review and some future research directions. J Geophys Res 110:F04S02. doi:10.1029/2004 JF000218

Blondel P (2009) The Handbook of Side Scan Sonar. Springer/Praxis, Chichester

Briggs KB (1989) Microtopographical roughness of shallow-water continental shelves. IEEE J Oceanic Eng 14:360-367. doi:10.1109/ 48.35986 
Briggs KB, Tang D, Williams KL (2002) Characterization of interface roughness of rippled sand off Fort Walton Beach, Florida. IEEE J Oceanic Eng 27:505-514. doi:10.1109/JOE.2002.1040934

Cazenave PW, Lambkin DO, Dix JK (2008) Quantitative bedform analysis using decimetre resolution swath bathymetry. In: CARIS 2008 International User Group Conference

Cazenave PW, Dix JK, Lambkin DO, McNeill LC (2013) A method for semi-automated objective quantification of linear bedforms from multi-scale digital elevation models. Earth Surf Process Landf 38: 221-236. doi:10.1002/esp.3269

Davis JP, Walker DJ, Townsend M, Young IR (2004) Wave-formed sediment ripples: transient analysis of spectral development. J Geophys Res 109:C07020. doi:10.1029/2004JC002307

Flemming BW (1988) Zur Klassifikation subaquatischer, strömungstransversaler Transportkörper. Bochum Geol Geotechn Arb 29:44-47

Fox CG, Hayes DE (1985) Quantitative methods for analyzing the roughness of the seafloor. Rev Geophys 23:1-48. doi:10.1029/RG023 i001p00001

Goda Y (2010) Random seas and design of maritime structures. World Scientific Publishing, Advanced Series on Ocean Engineering, vol 33

Hino M (1968) Equilibrium-range spectra of sand waves formed by flowing water. J Fluid Mech 34:565-573. doi:10.1017/ S0022112068002089

IMGW-PIB (2015) monitor.pogodynka.pl. Online hydrological and meteorological database of the Institute of Meteorology and Water Management-National Research Institute, Instytut Meteorologii i Gospodarki Wodnej-Państwowy Instytut Badawczy, Warszawa (accessed December 2015)

Knaapen MAF (2008) Local variation in the shape of superimposed bed forms as a function of local bathymetry. In: Parsons D, Garlan T, Best J (eds) Proc Marine and River Dune Dynamics III Int Worksh, 1-3 April 2008, Leeds, p 185-192

Knaapen MAF, van Bergen Henegouw CN, Hu YY (2005) Quantifying bedform migration using multi-beam sonar. Geo-Mar Lett 25:306314. doi: $10.1007 / \mathrm{s} 00367-005-0005-\mathrm{Z}$

Lefebvre A, Lyons AP (2011) Quantification of roughness for seabed characterization. In: Papadakis JS, Bjørnø L (eds) Proc 4th Int Conf \& Exhib UAM, 20-24 June, Kos, Greece

Lefebvre A, Ernstsen VB, Winter C (2011) Bedform characterization through 2D spectral analysis. J Coast Res SI 64:781-785

Lefebvre A, Paarlberg AJ, Winter C (2016) Characterising natural bedform morphology and its influence on flow. Geo-Mar Lett 36: 379-393. doi:10.1007/s00367-016-0455-5

Lisimenka A, Kałas M, Rudowski S (2013) Quantification of bedform roughnesses development in the Vistula river mouth using multibeam echousounder bathymetry data. In: Papadakis JS, Bjørnø L (eds) Proc 1st UA Int Conf \& Exhib, 23-28 June, Corfu, Greece, p 1421-1426

Lyons AP, Fox WLJ, Hasiotis T, Pouliquen E (2002) Characterization of the two-dimensional roughness of wave-rippled sea floors using digital photogrammetry. IEEE J Oceanic Eng 27:515-524. doi:10.1109/JOE.2002.1040935

Majewski W (2013) General characteristics of the Vistula and its basin. Acta Energetica 2(15):6-15

Massel SR (2013) Ocean surface waves: their physics and prediction. World Scientific Publishing, Advanced Series on Ocean Engineering, vol 36. doi:10.1142/8682

Michaelov G, Sarkani S, Lutes LD (1999) Spectral characteristics of nonstationary random processes - a critical review. Struct Saf 21: 223-244. doi:10.1016/S0167-4730(99)00022-3

Nordin CF, Algert JH (1966) Spectral analysis of sand waves. J Hydraul Div 92:95-114

Parsons DR, Best JL, Orfeo O, Hardy RJ, Kostaschuk R, Lane SN (2005) Morphology and flow fields of three-dimensional dunes, Rio Paraná, Argentina: results from simultaneous multibeam echosounding and acoustic Doppler current profiling. J Geophys Res 110:F04S03. doi:10.1029/2004JF000231

Percival DB, Walden AT (1993) Spectral analysis for physical applications. Cambridge University Press, Cambridge. doi:10.1017/ CBO9780511622762

Pruszak Z, van Ninh P, Szmytkiewicz M, Manh Hung N, Ostrowski R (2005) Hydrology and morphology of two river mouth regions (temperate Vistula Delta and subtropical Red River Delta). Oceanologia 47:365-385

Staśkiewicz A, Kałas M, Lisimenka A, Rudowski S (2010) Study of morphology changes in the Vistula river mouth area caused by flood in 2010 (in Polish). Maritime Institute in Gdansk Internal Report no 6569

Sverdrup HU, Munk WH (1947) Wind, sea, and swell. Theory of relations for forecasting. US Navy Hydrographic Office, HO Publ no 601

Van der Mark CF, Blom A (2007) A new and widely applicable tool for determining the geometric properties of bedforms. University of Twente, Enschede, CE\&M Research Report 2007R-003/WEM-002

Van der Mark CF, Blom A, Hulscher SJMH (2008) Quantification of variability in bedform geometry. J Geophys Res 113:F03020. doi:10.1029/2007JF000940

Van Dijk TAGP, Lindenbergh RC, Egberts PJP (2008) Separating bathymetric data representing multiscale rhythmic bed forms: a geostatistical and spectral method compared. J Geophys Res 113: F04017. doi:10.1029/2007JF000950

Vanoni VA, Hwang LS (1967) Relation between bed forms and friction in streams. J Hydraul Div 93:121-144

Venditti JG (2007) Turbulent flow and drag over fixed two- and threedimensional dunes. J Geophys Res 112:F04008. doi:10.1029/2006 JF000650

Wróblewski R, Rudowski S, Gajewski Ł, Sitkiewicz P, Szefler K, Kałas M, Koszałka J (2015) Changes of the Vistula River External Delta in the period of 2009-2014. Bull Marit Inst Gdańsk 30(1):16-22

Young I (1995) The determination of confidence limits associated with estimates of the spectral peak frequency. Ocean Eng 22:669-689. doi:10.1016/0029-8018(95)00002-3 